Article

\title{
Northern Research Policy Contributions to Canadian Arctic Sustainability
}

\author{
Alison D. Perrin ${ }^{1, *(\mathbb{D}}$, Gita Ljubicic ${ }^{1,2}$ and Aynslie Ogden ${ }^{3}$ \\ 1 Geography and Environmental Studies, Carleton University, Ottawa, ON K1S 5B6, Canada; \\ gita.ljubicic@mcmaster.ca \\ 2 School of Earth, Environment \& Society, McMaster University, Hamilton, ON L8S 4L8, Canada \\ 3 Polar Knowledge Canada, Cambridge Bay, NU X0B 0C0, Canada; aynslie.ogden@polar-polaire.gc.ca \\ * Correspondence: alison.perrin@carleton.ca
}

Citation: Perrin, A.D.; Ljubicic, G.; Ogden, A. Northern Research Policy Contributions to Canadian Arctic Sustainability. Sustainability 2021, 13, 12035. https://doi.org/10.3390/ su132112035

Academic Editors: Gail Fondahl, Grete K. Hovelsrud, Tero Mustonen and Stephanie Pfirman

Received: 2 September 2021

Accepted: 27 October 2021

Published: 31 October 2021

Publisher's Note: MDPI stays neutral with regard to jurisdictional claims in published maps and institutional affiliations.

Copyright: (C) 2021 by the authors. Licensee MDPI, Basel, Switzerland. This article is an open access article distributed under the terms and conditions of the Creative Commons Attribution (CC BY) license (https:/ / creativecommons.org/licenses/by/ $4.0 /)$.
Abstract: Academic research plays a key role in developing understanding of sustainability issues in the Canadian Arctic, yet northern organizations and governments struggle to find research that is relevant, respectful of local interests, and that builds local capacity. Northern science and research policies communicate expectations for how research should be prioritized, planned, conducted, and disseminated. They discuss northern leadership of research and outline the diverse roles that northerners and northern organizations could fill in research programs and projects. Many of these documents are founded on the need for research to improve environmental, economic, and social sustainability in the Canadian North and provide insight into how academia can support a northernled Arctic sustainability research agenda. The goal of this study is to examine northern research-policy documents to identify commonalities amongst the goals and priorities of northern organizations and their shared expectations for research in northern Canada. The objectives are to understand how organizations expect researchers to engage in and conduct research, how research programs can align with northern science policy objectives, and how academic research can support policy and decision-making related to sustainability. Through a quantitative content analysis combined with a qualitative thematic analysis, this comprehensive review examines research policy, strategy, guidance, and program documents produced by northern and northern-focused governments and Indigenous organizations. Relationships, partnership, and communication are the foundations of relevant and applicable research, requiring both resources and time for local and partner participation. Our analysis shows that researchers should consider potential policy applications for sustainability research early on in the development of research projects, ensuring that relevant local and policy partners are involved in designing the project and communicating results.

Keywords: northern research policy; research governance; research priorities; Arctic; sustainability; Yukon; Northwest Territories; Nunavut; Nunavik; Nunatsiavut

\section{Introduction}

Northern governments and organizations have identified the need for relevant research, accessible results, and engagement with northern communities as they increasingly focus on integrating evidence into decision-making [1-4]. Yet, northern organizations and governments struggle to find research that is relevant and is developed in a way that is respectful of local interests and builds local capacity [4-6]. Given the pressing importance of sustainability issues in the Canadian North, academic research can play a key role by contributing information to support sustainability transformations in the region [7-9]. However, there are gaps in understanding the relationship between sustainability research and practice, including how research can support sustainability policy and decision-making [7].

Northern experiences of research have been widely documented on a local scale, but not brought together as a whole in a way that enables a broad, transformative vi- 
sion for northern research $[4-6,10,11]$. There have been discussions within the scientific literature about improving how northern research is conducted in terms of individual projects [10-14]. However, the guidance and expectations coming from northern governments and organizations are generally not reflected within the academic literature; rather, they are captured in policy documents and grey literature. Systematic and realist reviews mainly capture themes and trends from available scientific literature based on literaturedatabase search protocols. This policy review seeks to contribute to a better understanding of northern Indigenous, organization, and government perspectives on research policy through a unique systematic approach to grey literature review.

There is a wide variety of organizations developing policies or providing guidance on research in northern Canada. There are strategy, guidance, and program documents produced by northern and northern-focused governments, Indigenous, and non-governmental organizations that discuss research policy. While there is a general discussion of research in these documents that applies to both Indigenous and non-Indigenous northerners, there is also an emphasis on research with Indigenous northerners, which is a result of both the colonial history of research and the importance of Indigenous rights across the North. Northern organizations often play a role in mediating how researchers engage with northerners, and their research-policy documents outline how they would like those relationships to unfold. Research-policy documents discuss northern leadership of research and provide insight into the diverse roles that northerners and northern organizations fill in research programs and projects. Through an analysis of these documents, we explore how organizations define and guide research in the Canadian North and the anticipated contributions of research to northern sustainability.

The goal of this study is to examine northern research-policy documents to identify commonalities amongst the goals and priorities of northern organizations and their shared expectations for research in northern Canada. The objectives are to understand how organizations expect researchers to engage in and conduct research and how research programs can align with northern science policy objectives. A related objective is to identify pathways for academic research to support policy and decision-making related to sustainability. This analysis examines the governance structures, policies, priorities, and organizations that guide, regulate, and interact with northern research. We identify themes related to principles, priorities, and guidelines, as well as the different steps in the lifecycle of a research project and the roles different actors play in research. It is clear that sustainability, particularly in terms of climate change and resource development, is a priority for northern regions. Research is identified as an important means of supporting sustainability transformations. Through this analysis, we provide insight into how academia can contribute to a northern-led sustainability research agenda that supports evidence-informed policy.

\section{Background}

Over the past sixty years, the Canadian North has been the focus of several national and international scientific programs and numerous government science strategies. Calls for a more coordinated response across northern jurisdictions are motivated by the impacts of resource development, sovereignty issues, and more recently, the impacts of increasingly rapid environmental changes [15-19]. Since the 1970s, efforts have been made by academia to articulate the need for a single unifying northern science policy that guides investments in northern research $[15,16,19]$. Serious gaps in Canadian Arctic research were identified in the 1990s [20], and from that realization, investments were made, including the International Polar Year and a northern research chair program. These were opportunities to build up northern research, invest in students, and develop robust research programs in the North.

Historically, northerners have felt left out of research decision-making in their region. Northerners, particularly Indigenous northerners, did not trust researchers due to a long history of poor or no communication, misunderstanding, and extractive research $[6,10,21,22]$. This distrust of research is directly related to the colonial legacy in the North, including 
loss of control over decision-making, land, and other aspects of their lives [4,23]. Poor communication and uneven power relationships have existed between researchers and communities, which contributes to ongoing distrust of the contemporary discussion of research and colonialism in the North $[4,10,11,24-27]$. The relationship between Indigenous northerners and research has been fraught with issues, for example, research data and results not being shared with participating communities, sensitive data being published without consultation, and researchers not attributing Indigenous or local knowledge to knowledge holders $[4,22,23,28]$. As Indigenous northerners have asserted governance and leadership in the North, this tenuous relationship has begun to change, but there are still uneven power dynamics.

The settlement of land-claim agreements and resulting self-government, co-management, and other expressions of Indigenous control over resource and land management, have influenced how northerners, in general, and Indigenous northerners, in particular, interact with research. This evolution in governance is reflected in an emerging dialogue about self-determination in research and a desire for control over both decision-making around research and guiding how research is conducted $[2,4,6,10,29,30]$. Indigenous research is intrinsically linked with governance, particularly control of the research agenda, whereby "Indigenous research ... is in itself an enactment of governance" [22]. Indigenous northerners have used research to challenge colonial policy, defend land rights, and contest resource development, often employing western academics and methodologies with Indigenous values and knowledge [22]. Although there are gaps in opportunities for northern Indigenous scholarship [7], Indigenous northerners are asserting their role as leaders in northern research $[13,31-36]$. There is a desire in the North for greater access to the necessary resources and facilities to conduct and manage research locally $[4,6,10,17,37]$. This includes support for research capacity for governments, co-management bodies, and institutes of self-government as they pioneer new forms of governance in the North [22,36]. Through the International Polar Year program, northern organizations saw opportunities to change how research was being done, to build partnerships to further their own research priorities, and to build northern research capacity through training and infrastructure $[14,38-43]$.

\subsection{Geographic Context}

While there are many different ways to delineate the Canadian North $[2,4,44,45]$, the geographic focus of this policy analysis includes five regions in northern Canada: Yukon, the Northwest Territories (NWT), Nunavut, Nunavik (the Inuit land-claim region in northern Québec), and Nunatsiavut (the Inuit land-claim region in northern Labrador) (Figure 1). We acknowledge that this excludes the northern provincial regions of British Columbia, Alberta, Saskatchewan, Manitoba, Ontario, Québec, and Labrador. Areas of the provincial North often face similar challenges in relation to sustainability issues. However artificial, political boundaries tend to frame policy jurisdiction, and thus, for the purpose of this study, the three territories, along with Nunavik and Nunatsiavut, were selected as our focus because they are most consistently included in pan-northern policies and publications.

The five regions of focus are all large in land area but have small populations, often with a majority clustered in the administrative capital while the rest of the population is spread throughout smaller communities [44]. In Nunavut, Nunavik, and Nunatsiavut, communities are mostly coastal and serviced by air and ship. In Yukon and the NWT, there is a mix of access, including year-round road, winter road, boat, and air. The three territories operate like provinces, with elected governments overseeing territorial programs and services, although some control lies with the federal government. Federal control of lands and resources was devolved to the Government of Yukon in 2003, giving the Yukon similar powers to the provinces, and to the Government of the Northwest Territories in 2014 [45-47]. Nunavut, which separated from the Northwest Territories to become a territory in 1999, is currently in devolution negotiations with the federal government to bring control of crown lands and resources to the territorial government [48]. Within the 
three territories, there are Inuit, First Nation and Métis land-claim and self-government agreements. Nunavik and Nunatsiavut are Inuit land-claim regions within the provinces of Québec and Newfoundland and Labrador, respectively.

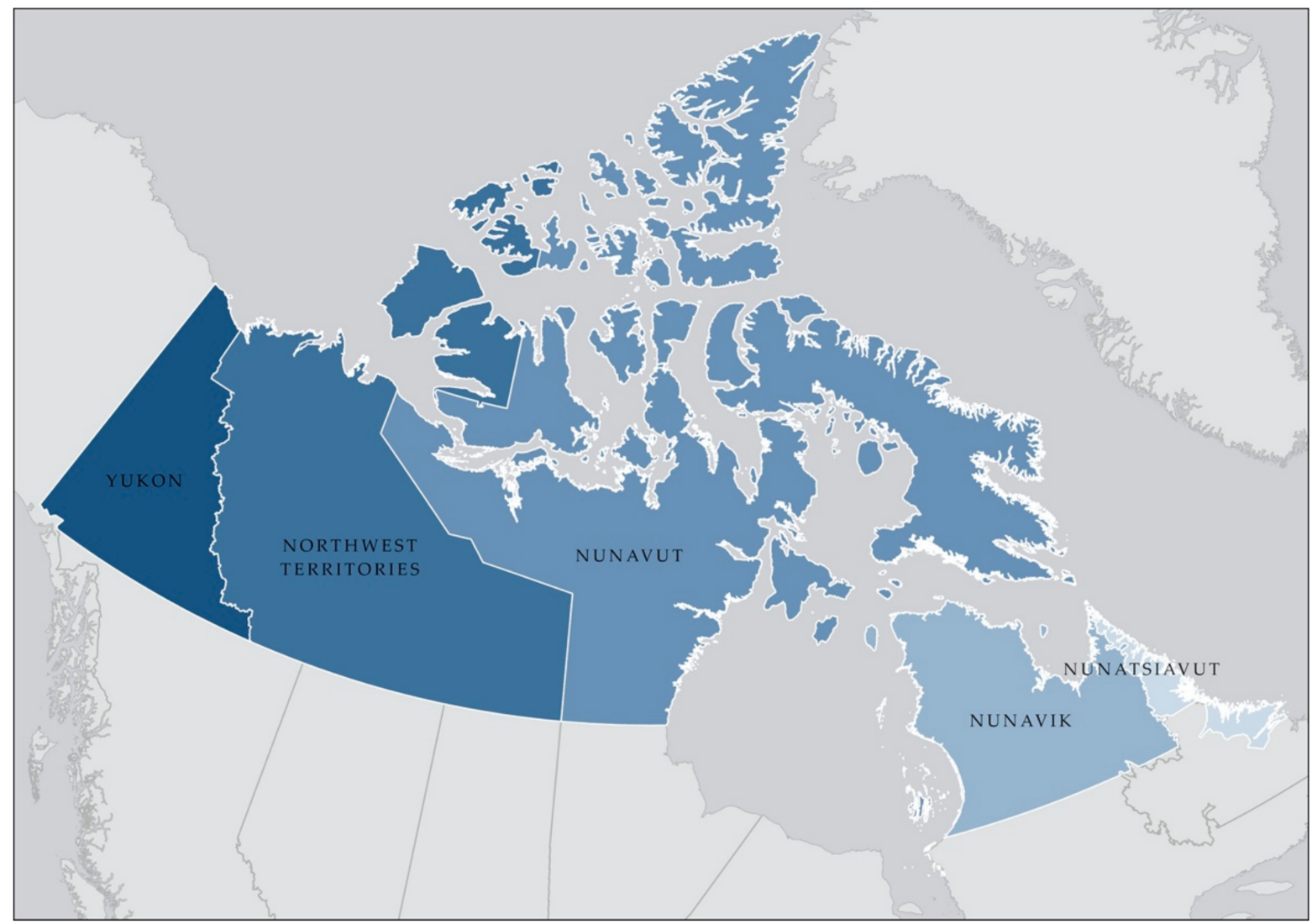

Figure 1. Map showing regions of northern Canada included in study.

Although the five regions of focus have distinct differences in terms of governance, cultures, and landscapes, they also experience similar challenges. Since the late nineteenth to mid-twentieth century, colonial expansion, resource development, and exploration were major sources of change across the northern regions in Canada. Colonization has had serious impacts on northern Indigenous peoples and their ways of life, including moving nomadic people into permanent settlements, forced relocations, land dispossession, the removal of children to attend residential schools, the impacts of physical and sexual abuse, intergenerational trauma, the loss of traditional cultures and languages, and the imposition of western governance systems [27,49-52]. However, since the 1960s and 1970s, Indigenous land-claim and self-government agreements have been driving innovations in Indigenous governance to achieve self-determination [45,49,53-57]. Indigenous governance is enacted in different ways across the North, and there are numerous different types of organizations that arose out of land-claim processes, including Indigenous governments, corporations, co-management boards, and institutes of public governance.

\subsection{Organizational Context}

Governance and responsibility over research in the North are spread amongst territorial and provincial governments, Inuit, First Nations, and Métis organizations and governments, federal agencies, academic institutes, non-governmental organizations, and the private sector. All these different actors can play roles in setting policy, providing guidance on how research should be done, distributing funding, and/or conducting research $[2,4,6,16,19]$. Government, academic, non-profit, and consultant research have all made considerable contributions to northern scholarship. Some research is being conducted 
by governments themselves or through consultants on behalf of governments or other organizations. This research is usually done to answer a specific question and under direct control of the contracting organization, and while some of it is tracked through research licensing or public reports, much of it is not publicly available. Policy documents, however, are a way of communicating needs, priorities, or expectations to those engaged in research that is not directly controlled by the organization. Such policy documents are particularly aimed at academic research, although they may be relevant to all types of researchers.

Historically, northern regions have relied on federal (or provincial) funding for science activities; however, they have recently started taking a more active role in shaping northern science by outlining expectations for research that is relevant, respectful, and solutionoriented $[4,6,58]$. The three territories, as well as Nunatsiavut, have research licensing or permitting processes that are designed to ensure that researchers consult with relevant rights- and stakeholders and that research does not cause environmental or societal harm. Research licenses provide an opportunity for northern governments, communities, and researchers to negotiate relationships and influence decisions around research [10].

Across all five regions, there are northern academic and research institutes that play a role in advancing northern science through their growing capacity to conduct and direct research [6,17]. Along with the territorial and regional research centres, there are numerous research stations across northern regions operated by universities, federal departments, and other organizations that engage in conducting research or hosting visiting researchers, including the Government of Canada's Canadian High Arctic Research Station (CHARS). The Canadian Network of Northern Research Operators (CNNRO) represents a membership of 31 operators and 10 associate members that range from community-based organizations to government departments and university-run research stations (e.g., Kluane Lake Research Station, Polar Environment Atmospheric Research Laboratory, Centre d'études nordiques) [59]. Across the North, there are non-governmental organizations (NGOs), often community-based, that are involved in conducting research (e.g., Ittaq Heritage and Research Centre, Institute for Circumpolar Health Research, Yukon Wildlife Preserve, and the recently closed Arctic Institute of Community-Based Research). There are also national and international NGOs that maintain northern research offices, including the Wildlife Conservation Society and the World Wildlife Fund. There are also a few research networks that are currently or formerly active in northern research and that greatly influence the research context. ArcticNet is a Network Centre of Excellence (NCE) focused on Arctic research in Canada that has recently initiated a funding program to support northern and Inuit-led research. The Canadian Mountain Network (CMN) is another NCE that is active in northern mountainous regions and offers several funding streams based on different modes of research, including Indigenous-led research.

\subsubsection{Yukon}

In Yukon, there are fourteen First Nations, eleven of which have settled land claims and finalized self-government agreements [60]. There are also several transboundary Indigenous groups from NWT and British Columbia with traditional territories and land claims in the Yukon. Some Yukon First Nations have research or Indigenous knowledge protocols and policies (e.g., Vuntut Gwitchin First Nation), and the Council of Yukon First Nations (CYFN) also has a number of research-policy documents. The Government of Yukon released their Science Strategy in 2016 and the Yukon Science Policy in 1986, both of which set out goals for developing research capacity in the Yukon $[3,61]$. The Science Strategy and online Compendium of Research and Monitoring are products of YG's Office of the Science Advisor, housed in the Executive Council Office [3]. The Yukon Scientist and Explorer's Act outlines requirements for research licenses, which are administered by the Government of Yukon's Department of Tourism and Culture [62]. The Act covers the physical and social sciences, with the exception of archaeological research, which goes through a separate permitting process. The Act applies to anyone "who enters the Yukon to undertake scientific research" [63], while researchers based in the Yukon are not required 
to apply for a license. There are also several other permitting or permissions processes that may be required in addition to a research license for research with wildlife, in parks or protected areas, or on Yukon First Nations' settlement lands. The Yukon is home to Yukon University, which recently transformed from Yukon College in 2020, and hosts campuses in most Yukon communities. The YukonU Research Centre, based in Whitehorse, is part of Yukon University and is focused on conducting research in the Yukon and across the North. There are also southern Canadian universities with Yukon-based headquarters, including both the University of Alberta North (a Yukon University partner) and University of Calgary's Arctic Institute of North America, which runs the Kluane Lake Research Station.

\subsubsection{Northwest Territories}

Negotiation of Indigenous land claims and self-government agreements is ongoing in the NWT, with many communities or regions having finalized their negotiations. Within the NWT, there are Inuit, First Nations, and Métis rightsholders. The Dene Nation is a coordinating organization that brings together First Nation governments in NWT, while the Inuvialuit Regional Corporation (IRC) represents Inuvialuit. Several Indigenous governments and land-claim organizations in NWT have research or Indigenous knowledge protocols and policies, and some have research offices within their governments (e.g., the Dedats'eetsaa: Tłicho Research \& Training Institute [64]). The Government of the Northwest Territories (GNWT) released a knowledge agenda in 2017 and a related action plan, which are coordinated and led by the Senior Science Advisor, housed within the Department of Environment and Natural Resources [1,65]. The knowledge agenda builds off an earlier science strategy with the same broad research priorities [66]. GNWT has a research partnership with Wilfrid Laurier University, which has offices in Yellowknife and an active research program in the territory. Aurora College is the main postsecondary institution in NWT, with campuses in several communities. The Aurora Research Institute (ARI) is part of Aurora College and hosts research centres in Inuvik, Fort Smith, and Yellowknife. ARI is mandated by the NWT Scientists Act to license and coordinate research in the NWT [67]. They operate a research ethics board (REB), and any researcher applying to conduct research with humans in NWT that is not going through a research-ethics approval process with their home institution is required to go through the REB process at ARI. The Dedats'eetsaa: Tłıchǫ Research \& Training Institute hosts Hotì ts'eeda, a Strategy for Patient-Oriented Research (SPOR) Support Unit funded by the Canadian Institutes for Health Research (CIHR) and governed by NWT Indigenous governments.

\subsubsection{Nunavut}

Nunavut became a territory as part of a land-claim process, and Inuit rights are recognized in the public government's mandate and through Inuit institutions of public governance $[45,68]$. The Government of Nunavut (GN) represents all Nunavummiut (residents of Nunavut), while Nunavut Tunngavik Incorporated (NTI) represents Inuit beneficiaries and is responsible for land-claim implementation and managing Inuit-owned lands. Nunavut's Scientists Act requires that researchers from all disciplines obtain a scientific license unless they require an archaeological permit issued under the Nunavut Act [69]. In addition to the research license, there are also separate permitting processes, depending on the type of research (e.g., wildlife, water, parks). When conducting research on Inuit-owned lands, a separate approval process is required through the relevant regional Inuit associations in addition to the research license [68]. The Nunavut Research Institute (NRI) administers the scientific research license in Nunavut, operates several research stations, supports visiting researchers, and conducts research in the region. The NRI is part of Nunavut Arctic College, Nunavut's postsecondary institute that has campuses across the territory and has recently partnered with Memorial University to provide degrees. Nunavut-based NGOs like the Aqquimavvik Society and the Qaujigiartiit Health Research Centre are actively involved in conducting research, as well as providing guidance on research ethics and methodologies. 


\subsubsection{Nunavik}

Nunavik is a land-claim area in the northern part of Québec and was the first of the four Inuit regions to sign a modern land-claim agreement as part of the James Bay and Northern Québec Agreement (JBNQA) in 1975. The Kativik Regional Government is a product of the JBNQA and is responsible for providing public services to the region, while Makivik Corporation is the land-claim organization established to represent Inuit beneficiaries [70]. Nunavik does not have a research license, but Makivik Corporation is currently leading the development of a regulatory system for research in the region. Makivik operates the Nunavik Research Centre based in Kuujjuaq, which collaborates with northern organizations and southern academic institutions to respond to research questions that directly link to community priorities and to support policy development by Makivik Corporation [71]. Université Laval also has two research stations in the region as part of its Centre d'études nordiques.

\subsubsection{Nunatsiavut}

Nunatsiavut is an Inuit land-claim and self-governing region within Newfoundland and Labrador. The Inuit of northern Labrador negotiated the Labrador Inuit land-claim agreement and self-government at the same time, resulting in the Nunatsiavut Government (NG) $[70,72]$. The NG is actively engaged in conducting research and regulates research through an advisory committee that reviews all proposed projects [73,74]. The Nunatsiavut Government operates the Nunatsiavut Research Centre in Nain, which hosts field and lab-based research conducted by NG staff, collaborators, and visiting researchers [73]. Memorial University is engaged in research partnerships in the region, particularly through the Labrador Institute and the School of Arctic and Subarctic Studies based in Happy ValleyGoose Bay.

\subsubsection{Government of Canada}

Even with devolution, the federal government still plays a key role in northern policy and programming, including through science, health, Indigenous services, and economic development. Science, resource development, and sovereignty issues have preoccupied federal government interest in the North for many years, leading to a range of political strategies and initiatives [45,75]. The current elected Government of Canada has developed an Arctic Policy Framework (APF), which replaces the previous federal government's policy document, Canada's Northern Strategy, and the Statement on Canada's Arctic Foreign Policy $[48,76,77]$. The APF provides overarching direction to the Government of Canada on priorities, activities, and investments in the Arctic, with a vision to 2030 [77]. Polar Knowledge Canada (POLAR), established to replace the Canadian Polar Commission, is the department that represents and coordinates the Government of Canada's Arctic science interests. They also facilitate a networked approach to northern research by bringing together other northern research centres and organizations. POLAR operates CHARS, provides research-project funding, and administers support for student research through the Northern Scientific Training Program [78]. The CHARS campus in Cambridge Bay, Nunavut is home to POLAR staff and visiting federal and academic researchers. There are numerous other federal government departments involved in administering, conducting, or supporting Arctic science, including Environment and Climate Change Canada, Health Canada, Natural Resources Canada (Polar Continental Self Program), and CrownIndigenous Relations and Northern Affairs Canada (Northern Contaminants Program and Climate Change Preparedness in the North).

\subsubsection{National Indigenous Organizations}

Inuit Tapiriit Kanatami (ITK) is the national organization that represents Inuit in Canada and works closely with the four Inuit regions that make up Inuit Nunangat (Inuit homeland within Canada): Nunavut, Nunavik, Nunatsiavut, and the Inuvialuit Settlement Region (in NWT) [79]. ITK's focus is on advocacy, research, outreach, and policy guidance 
on issues affecting Inuit, with a particular focus on Inuit relations with the Government of Canada [80]. ITK is engaged in science policy by advocating for better research practices, relationships, and outcomes within Inuit Nunangat. Research is one of ITK's current priority areas, and they have developed a National Inuit Strategy on Research (NISR) [4], among other research-guidance documents [49,81-84]. Self-determination in research is the backbone of the NISR, and the four Inuit regions have been directly involved in its development and implementation [4]. Through their own research programs, they support research in key topic areas, including health, education, and climate change. ITK has also played an important role advising ArcticNet, where they were instrumental in establishing Inuit research advisors. The Assembly of First Nations (AFN) represents First Nations in Canada nationally. They are involved in political advocacy but also play a coordinating role for First Nations on a number of issues. The First Nations Information Governance Centre (FNIGC) is an organization that promotes data governance in relation to First Nations, specifically the ownership, control, access, and possession (OCAP) principles. Although no longer operating, the National Aboriginal Health Organization (NAHO) also produced several documents promoting data governance for Indigenous Canadians. The NAHO had First Nations (FNC-NAHO), Métis (MC-NAHO), and Inuit centres (IC-NAHO) that addressed issues particular to each Indigenous group.

\subsection{Sustainability Context}

Arctic sustainability is a growing research area that aligns with many of the priorities articulated by northern governments and organizations. Yet, despite the numerous contributions this research area has already made, there are still big gaps in our understanding of sustainability in the Arctic [85]. A broadly accepted definition of sustainability includes meeting the needs of today without compromising the future $[8,9,86,87]$. However, there is no clear definition of what that means specifically for the North; it can have different meanings depending on the context of the discussion and the perspective of those involved $[9,88]$. Sustainability frameworks include several dimensions of sustainability, including sociocultural, economic, environmental, and institutional $[8,9,89]$. Indigenous sustainability frameworks incorporate holistic approaches to sustainability, emphasizing cultural values that are not necessarily inherent in western scientific-sustainability paradigms $[88,90]$.

Research that supports sustainability is a core goal shared by diverse organizations, despite differences in some of their specific sustainability priorities $[1,66,91,92]$. In northern research, sustainability is often linked with wicked problems characterized by long-term and complex interactions, such as climate change, resource development, health and wellbeing, impacts of colonialism and residential schools, and economic development $[7,86]$. Whereas these broad priorities are shared across the North, communities and regions have their own specific challenges and priorities, such as waste and water management, infrastructure, food or energy security, safe and healthy communities, housing, and economic diversity $[1,8,86]$. Although there is general agreement that environmental, sociocultural, and economic sustainability are important end goals for research, there are still knowledge gaps around how to achieve these transformations.

Northern governments and organizations have declared their interest in moving towards a science-policy framework that is informed by northern priorities and produces research that supports policy development, decision-making, and local action for environmental, sociocultural, and economic sustainability. The policy documents included in this analysis emphasize the importance of research that aligns with local needs, benefits local communities and regions, and produces research outcomes that improve the lives of northerners or affect broader change. In northern Canada, scientific knowledge is not the only type of evidence used in decision-making. "openness to alternative epistemologies creates a space for envisioning a future that is different from the present" [93]. Putting Indigenous knowledge at the forefront of policy development promotes resiliency in northern communities and prepares them to adapt to change. Indigenous knowledge is valued by the territorial governments as equal to scientific knowledge and has an equivalent role 
in informing evidence-based policy [1-3]. Sustainability transformations require action and policy-relevant research attuned to local needs and values. This policy analysis provides insight into the contributions of research to sustainability and how that can be improved to ensure that there are valuable outcomes from research in the North.

\section{Methodology}

Document analysis is a systematic method for reviewing and evaluating documents using qualitative interpretive analysis [94-96]. The document analysis undertaken in this project includes a focused review and thematic analysis of the policy documents typically found within grey literature. This policy review and analysis method was critical to gain insight into the context, values, and origins of northern research policies [94,97]. To clarify terminology, a policy is a decision, a commitment to a course of action, or a guideline for action that is based on a combination of values, beliefs, evidence, and political ideology $[98,99]$. Policy for science refers to all decision-making related to science or the systematic pursuit of knowledge, including research [99]. Policy documents provide insight into the priorities, values, and belief systems that guide decision-making within a government or organization, as well as identifying practical issues that are current and emergent $[97,98]$. The policy documents included in this study have a variety of uses, including communicating information on research in the North and the regulatory context, as well as providing insight into the goals, values, and motivations of the organizations that influence northern research. Therefore, documents were examined with attention to intention and credibility, including the purpose, the author, and the influence over actions or decisions [97]. For many northern-based organizations, science-policy documents are used to advocate for their research expectations and priorities, while in some cases, they communicate where an organization is focusing their research resources or how they approach their own research.

\subsection{Sourcing Documents and Inclusion Criteria}

We conducted a thorough online search using a common search engine and searching websites of known governments, Indigenous organizations, and non-governmental organizations (e.g., territorial governments, ITK, Dene Nation, CYFN). Documents were selected based on their relevance to the overall study goals and approach and according to three main inclusion criteria (Figure 2) [94,100-103]. The initial search identified 128 relevant documents; however, 18 were removed after reviewing the full text. Therefore, 110 documents were included for in-depth analysis. Most of the documents were in a standalone format (e.g., report, guide, pamphlet, discussion paper), but webpages were also recognized and included as policies when they discussed substantial policy information or guidance [104,105].

We aimed to be as comprehensive as possible, including all documents that met the inclusion criteria and were available digitally (see Supplementary Materials Table S1 for a list of documents, including author organizations and websites). We also recognize that there are limitations to the study based on our goals and approach, which focus on policies for research, as opposed to policies developed from research, and we therefore did not include research-program results [97]. We did not examine research funding programs and forms, which change regularly and are often updated or removed from the host website. We also did not include application forms for research licenses or protocols, which, in some cases, were the only documentation available from an organization (e.g., Nunatsiavut Government, Vuntut Gwitchin Government). For the federal and territorial governments, we focused on government-wide or corporate policies. These governments are actively conducting research in the North and may have additional departmental-level science policies that were not included within the scope of this study. There are potentially relevant policies being enacted by northern organizations that are either internal and not shared publicly or not documented in a written format and were therefore not part of this analysis. There are northern organizations and many First Nation governments that are actively 
involved in influencing, conducting, and guiding research in their region that are not represented in the study because no relevant policy documents were found online. Some of those organizations have information online about their involvement with research, but without extensive policy information, their webpages were not included in the study (e.g., Dechinta Centre for Research and Learning, Dedats'eetsaa: Tłı̨chọ Research and Training Institute).

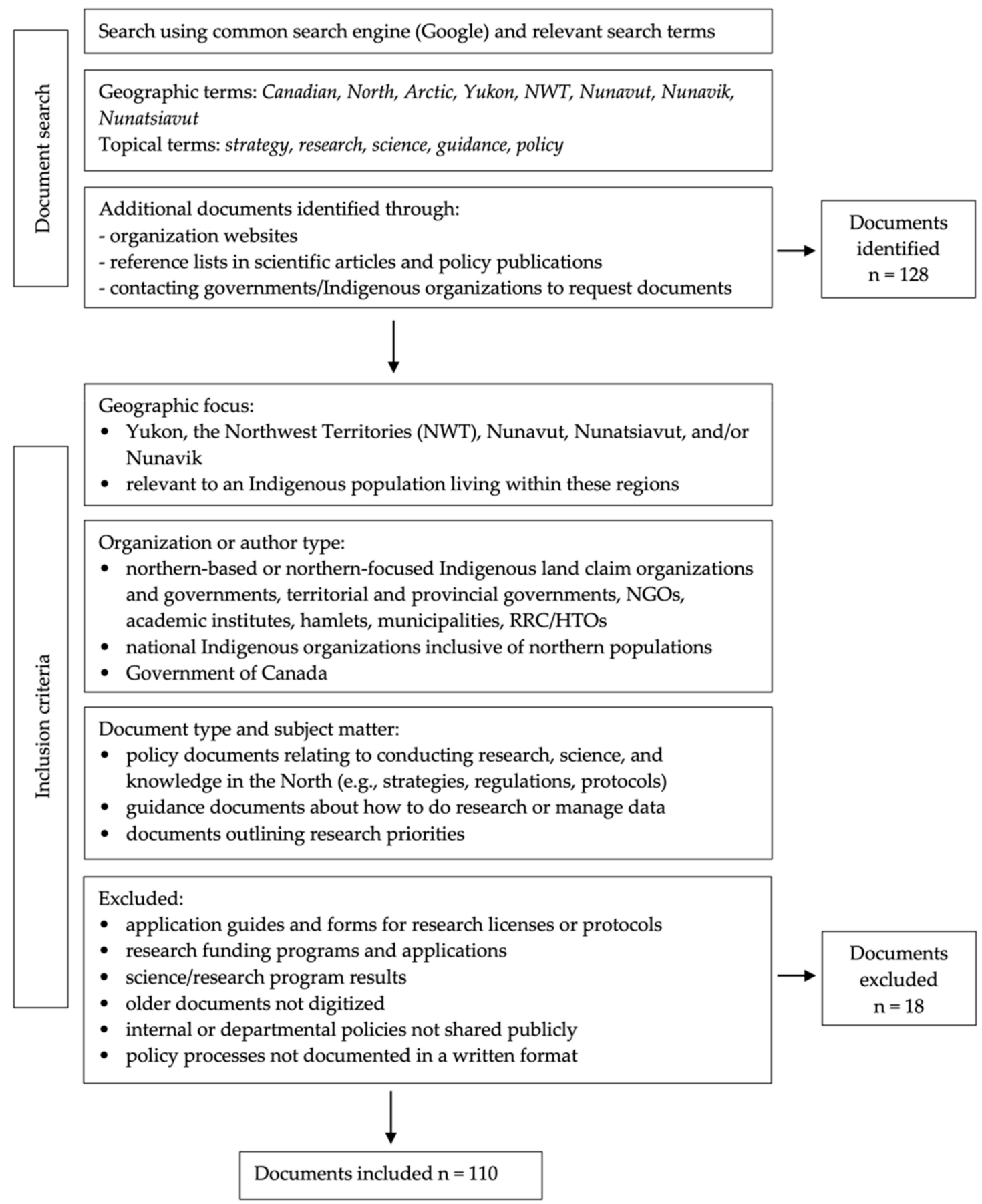

Figure 2. Document-sourcing and screening process.

\subsection{Coding}

In the process of reviewing relevant documents, descriptive information related to each document was recorded in an Excel spreadsheet to track and categorize documents, as well as to assist with initial analysis. These include author type, geographic scale (regions it 
is relevant to), publication focus and type (policy, research priorities, or research guidance), discipline focus, relevance to or focus on Indigenous peoples, mention of Indigenous knowledge and local knowledge, and focus on local or regional protocol or research license. Descriptive statistics were produced in Excel to provide insight into the types of documents that exist and their geographical and topical coverage. These characteristics were then entered as document attributes in NVivo to be used in the thematic analysis.

The coding process combined a deductive and inductive approach. An initial coding scheme was developed based on a literature review focused on research issues and approaches relevant to the North, and new codes were created as they emerged during the coding process. Research-planning and guidance documents were used to identify the different steps in the lifecycle of a research project and the types of actors that are involved in northern research. A comprehensive list of codes (Appendix A Table A1) guided the coding process, including codes relating to: (i) elements of the research project lifecycle (e.g., research design and approval, conducting research, sharing results); (ii) concepts relevant to research practice (e.g., partnership, community engagement, participation, capacity building); and (iii) roles that different actors play in northern research (e.g., funder, regulator, student). Within the groups of codes, there are parent codes that represent general or broad themes and subcodes that are more specific. Codes were applied when concepts were named explicitly but also through interpretation when a concept was discussed without using key terms. We created a clear description of each of the codes to help reduce error and bias in the coding process. Documents were coded in NVivo software, which supports document analysis by enabling the comparison of document codes and attributes within a large number of documents. Using NVivo, we explored relationships between codes and attributes and compared themes across regions and author types using crosstab queries. We compared the three types of codes to get a better understanding of how key concepts should be applied to the steps of a research project and which actors should be involved.

\section{Coding for Sustainability}

Sustainability was identified early in the coding process as a driving issue for northern research. It was added to the coding framework and tracked throughout the documents, providing insight into research priorities. Sustainability was coded by searching for explicit mentions of the word sustainability, as well as coding for discussions of issues or priorities related to complex changing environmental, sociocultural, or economic conditions. Environmental sustainability issues included impacts of climate change, resource development, and shipping. Sociocultural sustainability was identified in relation to issues like community well-being, health disparities in the North, food and water security, and cultural concerns like language revitalization. Economic sustainability was discussed in relation to economic diversification, tourism, institutional research capacity, and funding stability.

\subsection{Description of Documents}

The analysis focused on several types of documents, including strategies, action plans, discussion papers, reports, guides, statutes, information brochures, and webpages (Figure 3). Some of these documents communicate internal policies, such as how an organization will support and fund research or how they will incorporate science into decision-making $[1,3]$. Other documents communicate guidance or expectations to external stakeholders, for example, by discussing concerns with current research practices and expectations for how research should be conducted. Some research-guidance documents outline internal policies on how an organization approaches their own research [106,107], while others provide guidance to external researchers or organizations in conducting research [108-110]. Most of the documents were produced from 2000 onwards (91\%). This temporal scope reflects the limited availability of digital documents prior to that time period, the project focus on contemporary science policy, and the more recent emphasis by various organizations on articulating science and research policy. 


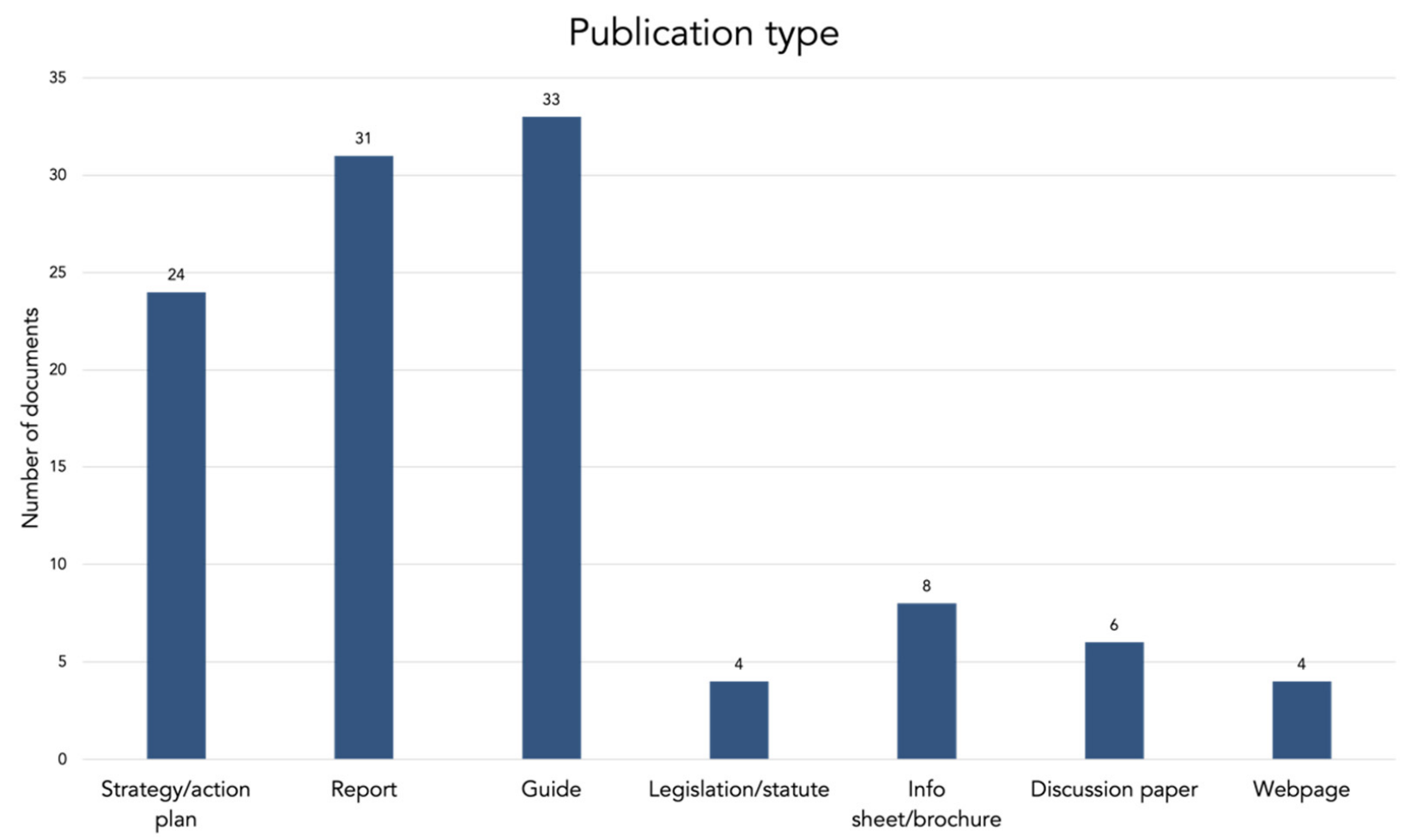

Figure 3. Documents analyzed according to publication type, $n=110$.

Most of the documents (88, or $80 \%$ of the total) focused on research in general, although there were also some with a discipline-specific focus, including social sciences $(4 \%)$, humanities $(2 \%)$, health research $(16 \%)$, physical and natural sciences $(3 \%)$, and Indigenous research (meaning research using Indigenous research methodologies) (6\%). Some of the policy documents communicate a protocol or provide guidance on how to apply a protocol, such as Indigenous knowledge (or Traditional knowledge) protocols and policies and regional research licensing protocols. Documents produced by the Canadian Arctic Research Licensing Initiative (CARLI), which reviewed the licensing and permitting processes in the three territories during IPY, were also included in this category. Although they are not regulatory documents themselves, they provide information on regulatory processes. Protocols and associated documents were communicated through different types of publications, including legislation, guides, and information sheets (Figure 3). Within the 110 documents reviewed, 19 were about a protocol at the regional or pan-Arctic scale, while 6 were focused on a local protocol targeted at a community or a subregion.

All documents were tracked according to author type (Figure 4), and any documents produced by a consultant on behalf of another organization were included in the main author type of the organization that initiated the document (e.g., NGO documents cited under the individual author's name). Most of the documents we reviewed were produced by the Government of Canada (27\%), including by POLAR, the Canadian Polar Commission, and federal advisory boards (e.g., Science Council of Canada). National Indigenous organizations produced $19 \%$ of documents, including organizations that represent and advocate for Inuit, First Nations, and Métis on the national or pan-northern scale (e.g., ITK, AFN). Regional and local Indigenous governments produced $17 \%$ of documents, including Indigenous governments, Indigenous land-claim and co-management organizations, and other northern Indigenous organizations (e.g., Sambaa K'e Dene Band, NTI, Gwich'in Renewable Resources Board (GRRB), CYFN). Documents produced by the territorial governments $(13 \%)$ include policies produced by the governments of the Yukon, NWT, and Nunavut. Northern NGOs (13\%) include regional and community-based non-profit organizations that are involved in research (e.g., Arctic Institute of Community-Based Research, Qaujigiartiit Health Research Centre). Northern academic institutes (6\%) include 
the northern colleges, universities, and research institutes (e.g., Aurora Research Institute, Yukon Research Centre). Southern NGOs (5\%) include documents produced by associations focused on northern research (e.g., Association of Canadian Universities for Northern Studies, International Arctic Social Sciences Association). Southern academic institutes $(2 \%)$ include documents produced by research networks led by southern universities (e.g., Resources and Sustainable Development in the Arctic (ReSDA), Yukon Initiating Group of the Canadian Mountain Network). The one provincial government document (1\%) was produced by the Gouvernement du Québec and relevant to Nunavik. Two groups that were identified as potential author types but did not produce policy documents included in this study include renewable resource councils/hunter and trapper organizations (RRC/HTOs) and communities/hamlets.

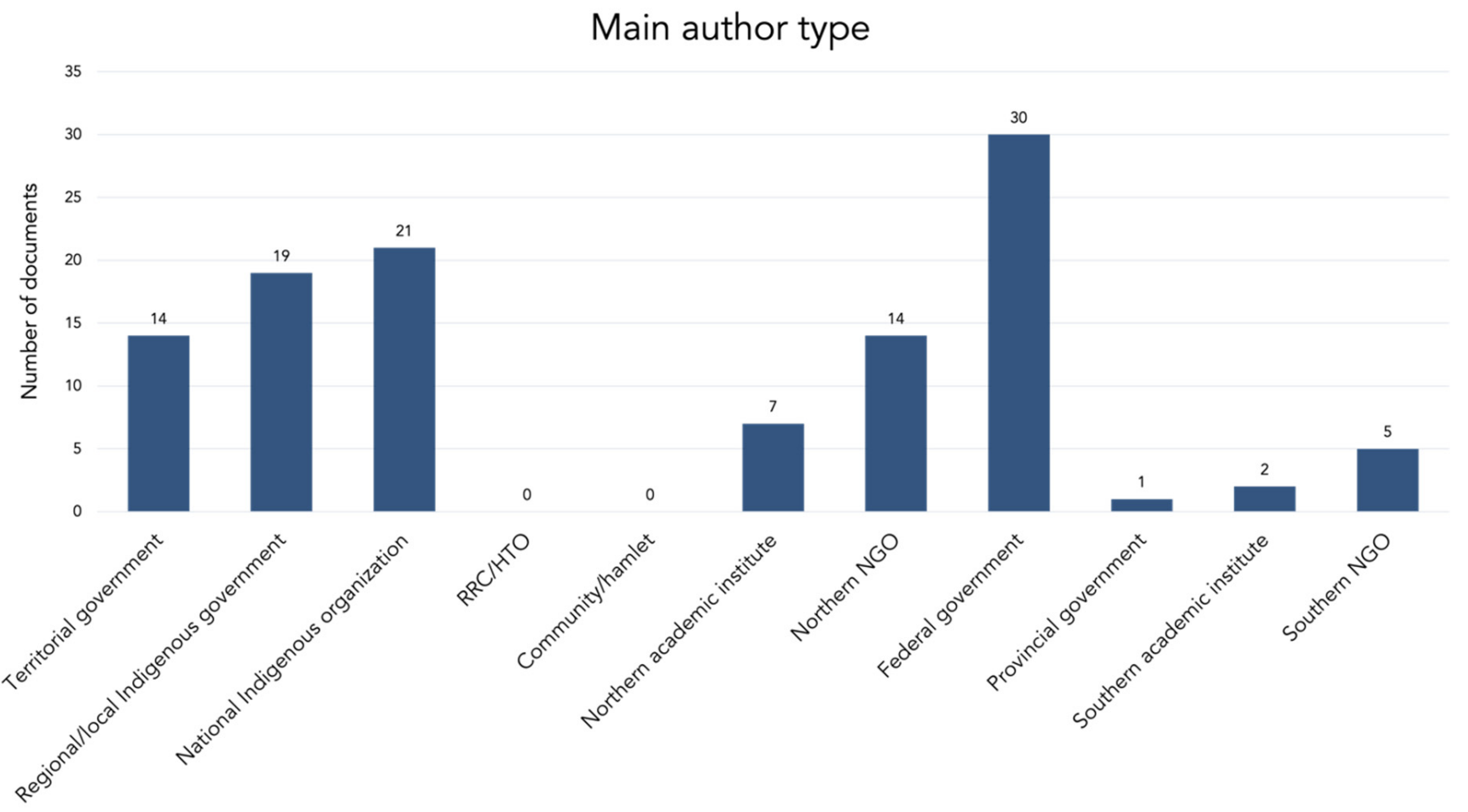

Figure 4. Documents analyzed according to author type, $n=110 *{ }^{*}$ Number of authors is larger than the total number of documents as 3 documents are co-authored.

In terms of geographic coverage, half of the policy documents analyzed have a pannorthern focus, with many others having a regional focus (Table 1). Far fewer focus on the subregional level, with only one focused on the community level. Furthermore, the documents analyzed are relevant across the five northern regions (Figure 5). Of the 53 pannorthern documents, 27 were focused on all five regions and were mainly produced by the Government of Canada, southern NGOs, or southern academic networks. However, some of the pan-northern documents focused on a subset of regions, usually either at the pan-territorial scale (the three territories) or Inuit Nunangat scale (the four Inuit land-claim regions). The only region-specific document identified in this study for Nunavik was the Québec research and innovation strategy 2017-2022 [111], and none was identified for Nunatsiavut. All other documents coded to those two regions are pan-northern, either focused on all five regions or across Inuit Nunangat. Although the Inuvialuit Settlement Region (ISR) is geographically in the NWT and the Yukon, settled Inuvialuit communities are all in the NWT, so relevant documents were coded to the NWT. There are two exceptions: the documents produced by the Wildlife Management Advisory Council (North Slope), a co-management board related to the Inuvialuit Final Agreement, are specific to the Yukon North Slope region of the ISR but relevant to the Inuvialuit population in NWT and were therefore coded to both the Yukon and NWT. 
Table 1. Documents according to regional-scale coverage, $n=110$.

\begin{tabular}{ccc}
\hline Regional Scale & Number of Documents & Description \\
\hline Pan-northern & 53 & Relevant to 2 or more regions \\
Regional & 43 & Relevant to a region (Yukon, NWT, Nunavut, Nunavik, or Nunatsiavut) \\
Sub-regional & 13 & Relevant to a subregion or traditional territory (e.g., ISR) \\
Community & 1 & Relevant to a single community \\
\hline
\end{tabular}

\section{Regional relevance}

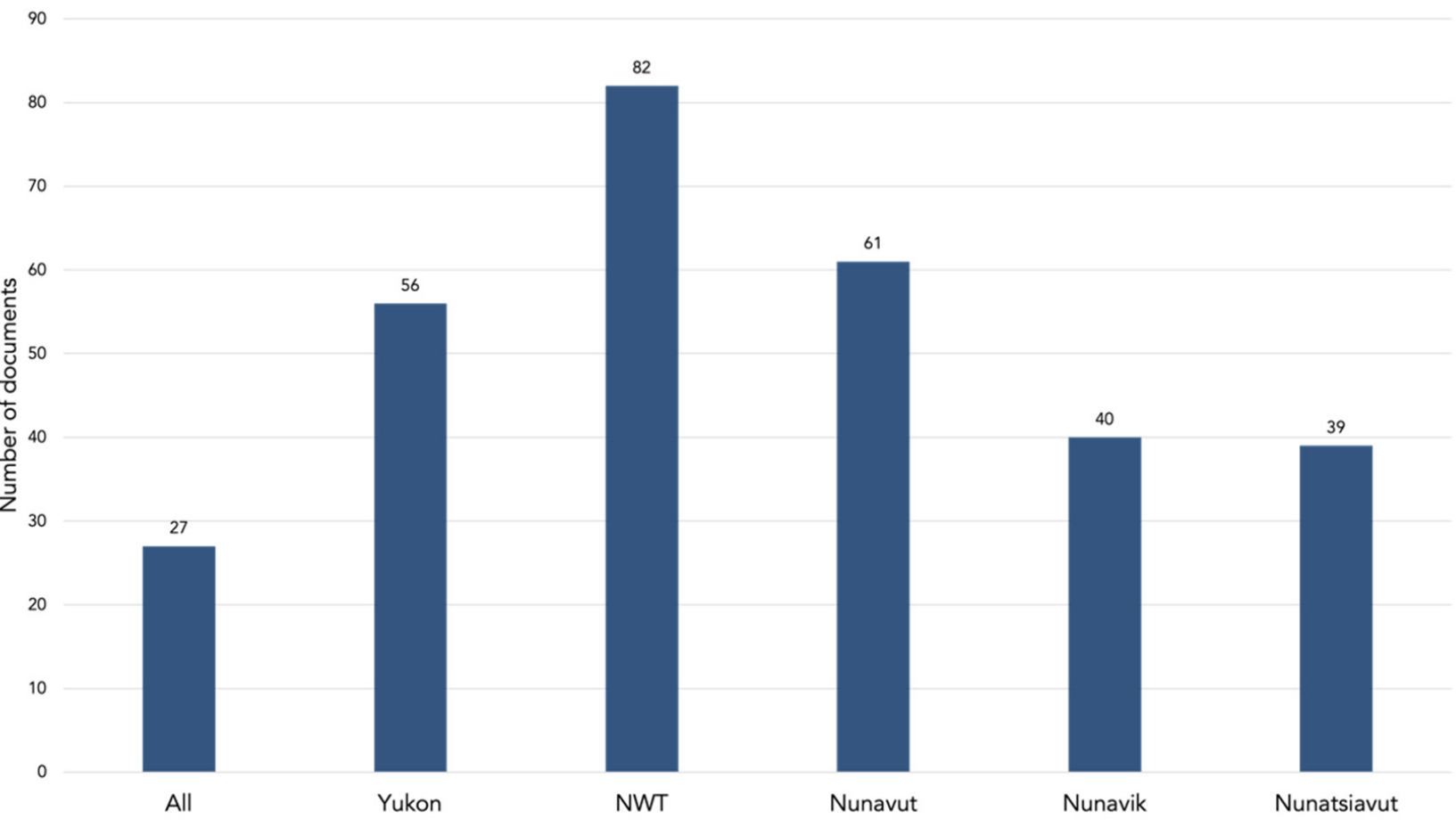

Figure 5. Documents analyzed according to regional relevance, $n=110$.

\section{Results}

The coding process and thematic analysis identified key themes discussed throughout the documents, although diverse lenses were applied to these concepts. The most commonly identified codes include partnership, Indigenous knowledge, research capacity, communicating research, governance capacity, consultation engagement, informing policy decisions, outcomes of research, research benefits, and training (Figure 6). Partnership was emphasized most (in 86 documents), followed by Indigenous knowledge (76), research capacity (72), and communicating research (69), while the remaining codes were evenly distributed (66-64). Several codes are related to the impact that research has (informing policy decisions, outcomes of research, research benefits) or the context in which research is conducted (research capacity, governance capacity), while others focus on approaches to research (partnership, communicating research, and consultation engagement). Two of the codes were related to the steps in a research project lifecycle (informing policy decisions, communicating research), but none was from codes related to roles in research. Many of the documents reviewed discussed the role of researchers generally, without specifying specific types of researchers. There were also numerous mentions of Elders, students, local researchers, and local coordinators, yet the occurrence was much lower than codes from the other two categories. 


\section{Top ten codes overall}

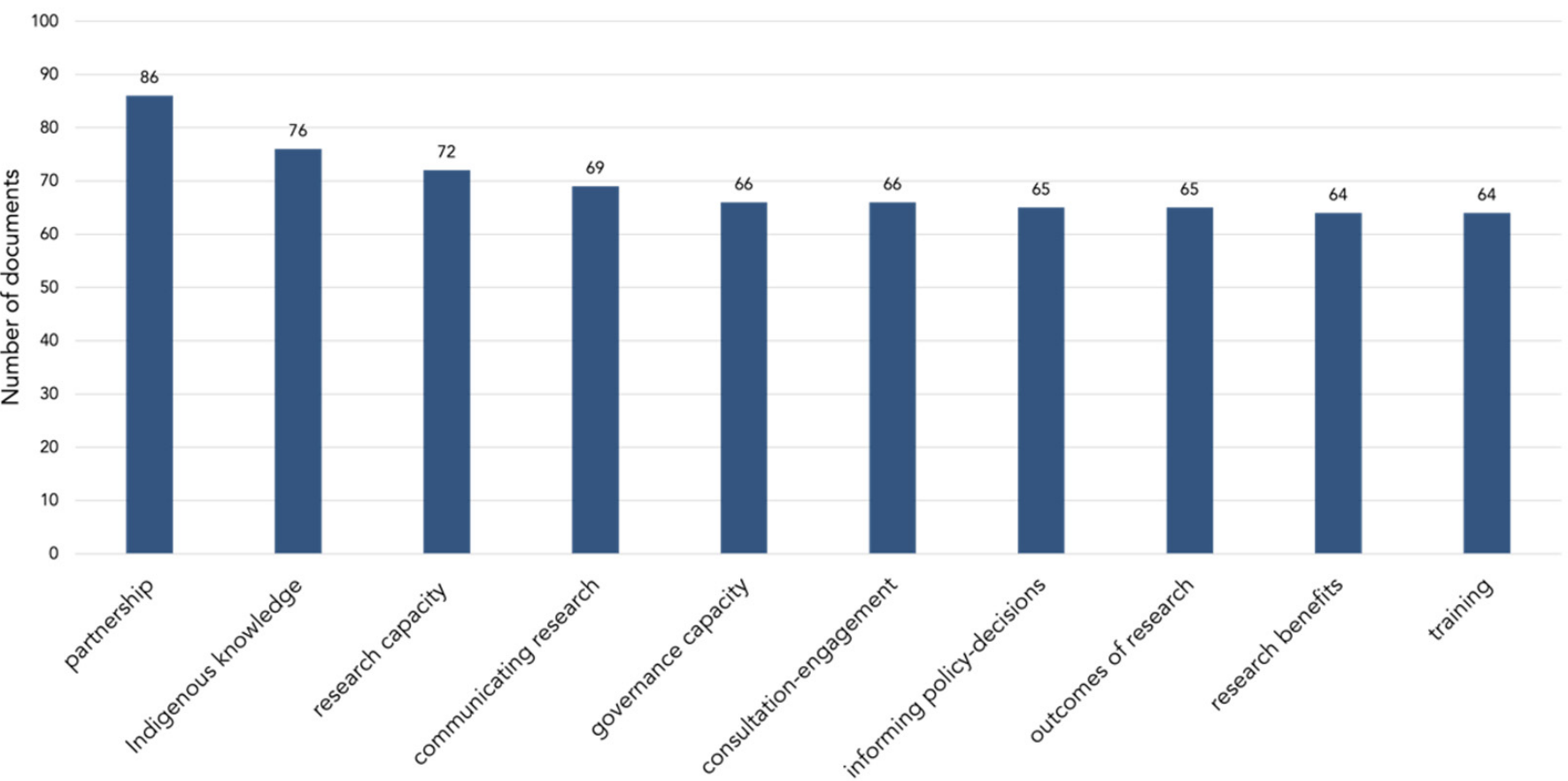

Figure 6. Top ten codes used overall by number of documents they are referenced in.

The top ten codes were then cross-referenced with document attributes to explore how they were prioritized by region (Figure 7) and author type (Figure 8). The number of coded documents was compared as a percentage of the total number of documents per region and author type.

\section{Top 10 codes by region}

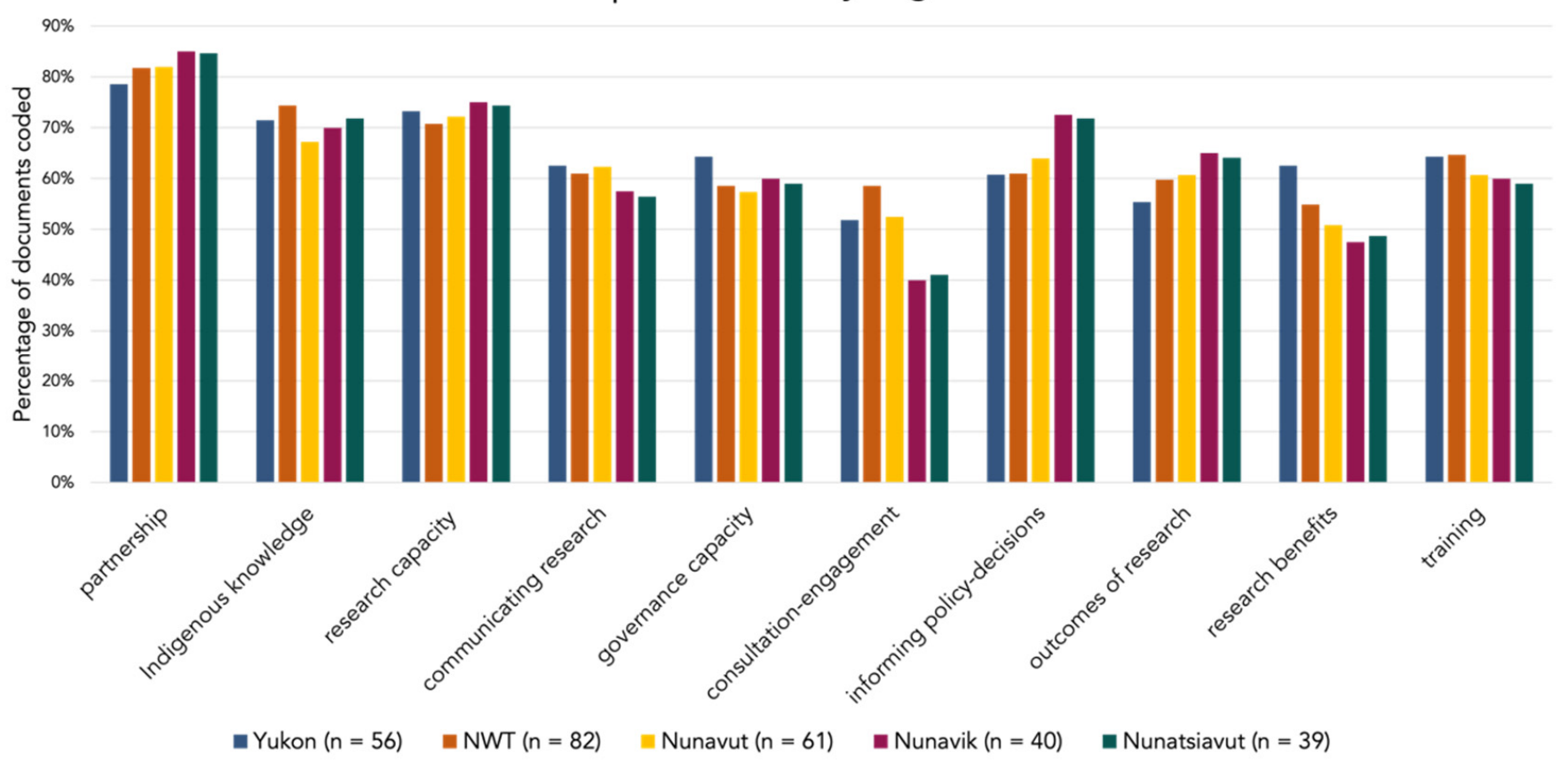

Figure 7. Top ten codes analyzed by region. 


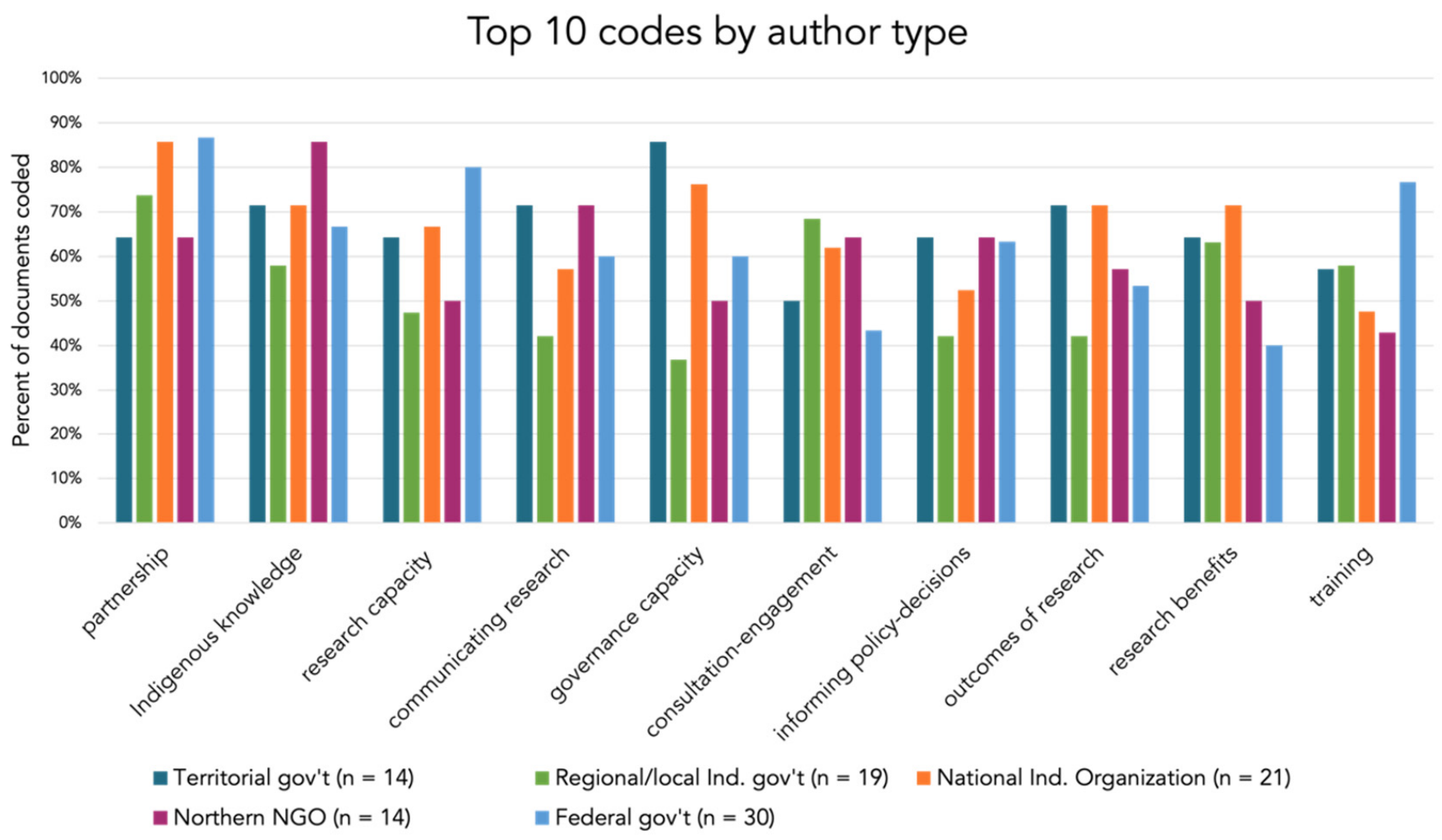

Figure 8. Top ten codes analyzed by author type.

There is not a lot of variation amongst the top ten codes overall across the five regions (Figure 7). There is a slightly greater importance put on governance capacity and research benefits in documents relevant to the Yukon, on consultation engagement and Indigenous knowledge in documents relevant to NWT, and on informing policy decisions and outcomes of research in documents relevant to Nunavik and Nunatsiavut (Figure 7). We analyzed the documents related to each region separately to identify the most-used codes in each region, and seven of the top ten codes ranked consistently high in all regions, including partnership, Indigenous knowledge, research capacity, informing policy decisions, governance capacity, and communicating research. Other themes with regional importance were northern participation (Yukon, NWT, and Nunavut), and research agreements (Nunavik and Nunatsiavut).

There was more variability in the thematic coding when the top ten overall codes were cross-referenced by the five most common author types (Figure 8). Indigenous knowledge and communicating research were more commonly coded in documents produced by northern NGOs (Figure 8). Many of these organizations centre Indigenous knowledge or, at the very least, emphasize its importance in their research approach. Communicating research is an important role for northern NGOs (Figure 8), many of which focus on research with communities and Indigenous northerners, often promoting participatory methodologies that require ongoing communication throughout the research project.

Governance capacity was emphasized by territorial governments and national Indigenous organizations as a key focus for research in the North (Figure 9). For northern governments, this directly relates to their role in legislating research in their own regions and advocating for relevant priorities in federal research programs. For national Indigenous organizations, this was discussed in relation to individual research projects and data management $[4,112]$. They also identified some of the challenges that communities or Indigenous organizations face when engaging in processes that govern research, such as advising on funding programs, participating in research committees, or advocating for priorities in federal research programs. Whereas larger organizations may have the capacity to engage in these processes, supports are required for many Indigenous organizations or 
community members to participate, including funding for positions, training for necessary skills, or the opportunity to take part in relevant boards and committees [4]. National Indigenous organizations also focused on how research is done, with an emphasis on partnership and research benefits (Figure 8). The federal government emphasized partnership, research capacity, and training, often in relation to their role supporting other organizations to participate in research.

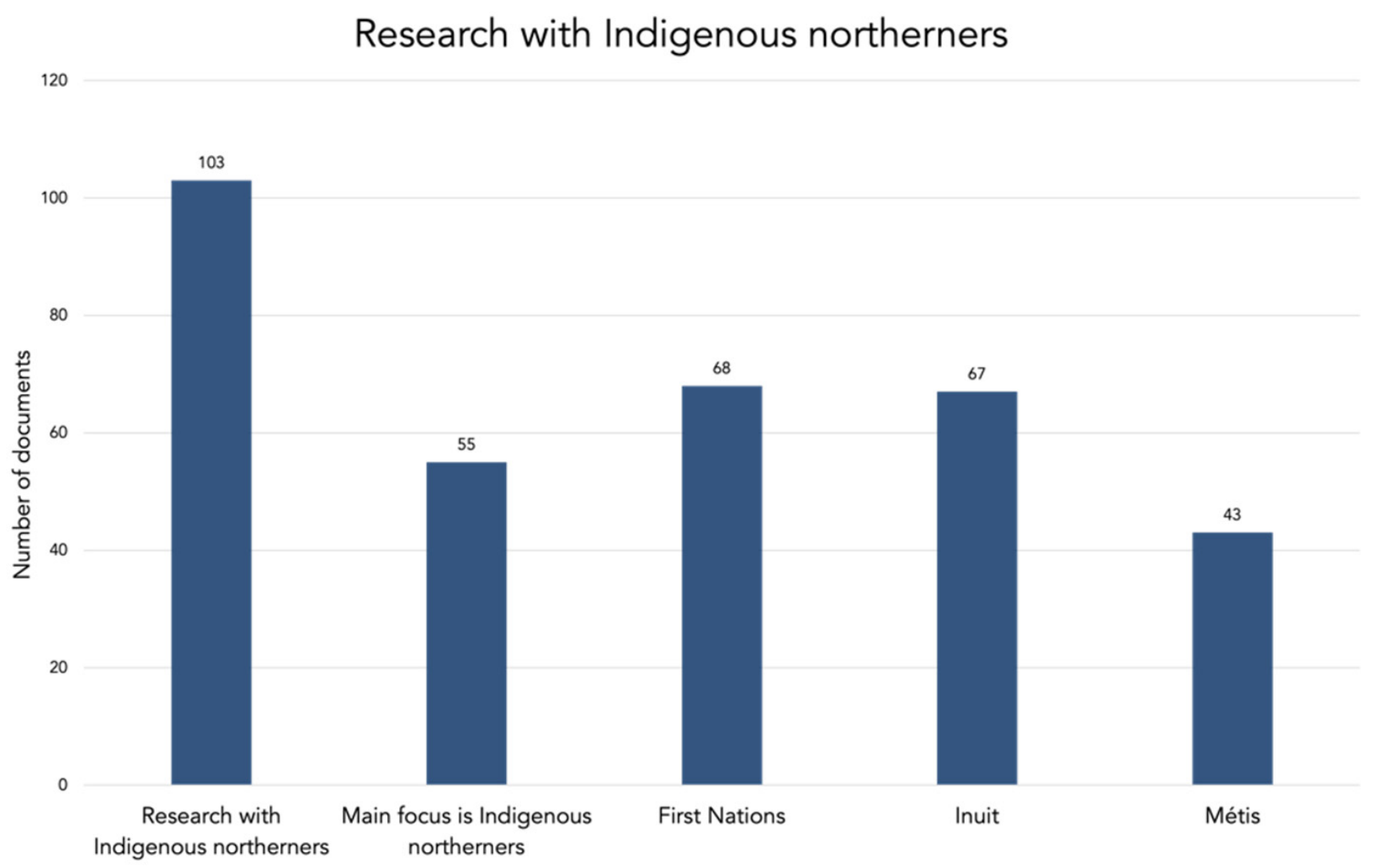

Figure 9. Documents that include discussion of research with Indigenous northerners.

The major themes identified through the coding analysis are explained and explored in detail in the following section. The main theme of partnership is explored in Section 4.1 as a foundational element of research relationships. Indigenous knowledge and how Indigenous northerners are included in these documents is the focus of Section 4.2. Research and governance capacity are interrelated and are explored together in Section 4.3, along with training. The outcomes of research, including research benefits, are discussed together in Section 4.4. Informing policy decisions was a major theme that required a separate analysis from the other outcomes of research and is discussed on its own in Section 4.5. Communicating research and consultation engagement are discussed together as related themes in Section 4.6.

\subsection{Partnership as the Foundation for Research Relationships}

Partnership is identified as a key component of research, although it is rarely defined or contextualized within the policy documents we reviewed. Generally, the concept of partnership is presented in relation to researchers and their relationships with other stakeholders, particularly in terms of developing strong researcher-community partnerships. However, there is also a discussion of the role partnerships can play in governing research, including relationships between governments, other organizations, and communities in setting expectations for research, guiding priorities and topics, and developing northern research programs. In the analyzed documents, the theme of partnership is highly related to the steps in the research-project lifecycle that are involved in developing relevant, use- 
able research, such as identifying priorities and goals for the project, informing policies and decisions, and communicating research.

National Indigenous organizations like ITK, AFN, and the Métis and First Nations centres of the NAHO, emphasize the importance of partnership in research. These organizations advocate at the national scale for Inuit, First Nations, and Métis to be equal partners in research. "In order to truly benefit from research focusing on our people, Inuit must be included as equal partners with researchers at every step of the process" [113]. Partnerships are a means of achieving research goals where capacity is limited for researchers, communities, and northern organizations. Trust, respect, and accountability are identified as integral to a research partnership, and northern participation in research projects was also identified as a core priority. Research relationships can be challenging, but as described by the MC-NAHO [114], "Support and commitment from both sides are needed for quality research ... a mutual commitment between researchers and communities to resolve these issues ... will ensure that the process is respectful."

In an era of Indigenous self-determination in research, Indigenous partners have expectations for how research projects will unfold. Research agreements are recommended as a tool to facilitate partnerships and ensure that community and partner needs are considered, along with the needs of the researcher. However, formal agreements were not discussed as frequently as the importance of building good relationships. A research agreement does not create a relationship; it is a way of formalizing a pre-existing relationship by clearly outlining expectations of all involved. Although a research agreement may not be a place to outline all aspects of the relationship, it can include a process for dealing with challenges and negotiating conflicts if they arise during the project. It is also an opportunity to document plans for storing, using, and sharing data, which has been a contentious issue between Indigenous communities and researchers in the past [112,115]. In some cases, research agreements are required, particularly when communities have a protocol for working with Indigenous knowledge [116-118].

Partnerships are a key factor affecting both governance and research capacity in the North. For the Government of Canada, partnership and governance capacity arose as themes in terms of Canada's relationship with other circumpolar countries, particularly the United States [76]. However, in recent documents produced by the federal government, more focus is placed on the relationship they have with northern governments and ITK. For northern governments and ITK, partnership is an essential component of their capacity to govern or influence the northern research agenda. Each government or organization only operates within its specific sphere of influence (e.g., as a regulator, funder, research agency, or partner) and must look to other governments for those areas where they do not have direct influence. This means that organizations can outline expectations and priorities for research but need to work with others to achieve and promote them. As an example, ITK [4] promotes Inuit self-determination in research by working with partners like governments, universities, research institutes, and academics to enhance the outcomes of research for Inuit. Specifically in relation to the Government of Canada, "the development of an Inuit Nunangat research policy is necessary to coordinate research initiatives among the more than 10 federal departments and agencies that carry out Inuit Nunangat research, and to formalize guidelines for advancing Inuit governance in research" [4].

This approach to partnership is necessary, yet it is also fraught with challenges. In her work on the consultation process for the development of the Arctic Policy Framework, Mary Simon heard numerous concerns about a lack of accountability by the Government of Canada to these relationships:

"I encountered in my discussions a profound sense of disillusionment, and sometimes distrust, related to agreements with the Government of Canada ... The term co-development of policies with Canada was looked upon with suspicion. My overall impression was that there was a longstanding disconnect between the aspirational intentions and commitments of Ministers, and the paternalistic, 
at times obstructionist, approach by the bureaucracy to the implementation of these ideas." [119]

Within the policy documents produced by Government of Canada, there is a changing discourse in relation to partnership that highlights changes in how they approach partnerships, including the recognition of community and regional priorities [48,120].

The contributions of partnerships to the research capacity of northern individuals, communities, and organizations are well documented; however, they can benefit researchers as well. As northerners gain comfort with research and find new ways to contribute to projects, there is more interest in seeking out research opportunities for their communities. As outlined by the GNWT, "The creation and sharing of knowledge is an important legacy for any research project; however, capacity-to plan, initiate and participate in research-is also an important legacy. If researchers are able to share their approaches, ideas and successes the stage will be set for more positive community involvement in research and monitoring in the future." [121]. Local organizations can provide key supports to researchers through partnership if research goals are relevant to the community [99,107]. Reciprocity in research relationships is a fundamental principle for research with Indigenous communities $[110,122]$, and the ability to meet the needs of both the researcher and community is emphasized as part of a strong partnership.

\subsection{Indigenous Knowledge in Relation to Research}

Most of the reviewed documents recognize Indigenous northerners as a key population for consideration in relation to research, with 103 documents (94\%) at least mentioning or discussing research with Indigenous northerners (Figure 9). Many of these documents had a pan-Canadian focus and were relevant to all northern Indigenous populations, as well as non-Indigenous northerners, while others were regionally or locally specific. A few documents are not specific to the North but focus on research with First Nations or Métis on a national scale, and therefore have relevance for First Nations and Métis living in northern Canada. These include documents produced by AFN, FNIGC, the FNC-NAHO, and the MC-NAHO. Pan-northern documents that had relevance to all five regions and did not specify a specific Indigenous group were coded to First Nations, Métis, and Inuit. For regional documents, those relevant to the Yukon were coded to First Nations; those relevant to Northwest Territories were coded to First Nations, Métis, and Inuit; and those relevant to Nunavut, Nunavik, and Nunatsiavut were coded to Inuit. Overall, 68 of the 110 documents (62\%) were relevant to First Nations, $67(61 \%)$ to Inuit, and $43(39 \%)$ to Métis (Figure 9).

Of the documents that mention or discuss research with Indigenous populations, $55(50 \%)$ have research with Indigenous northerners or Indigenous peoples as the main focus of the document (Figure 9). These include Indigenous knowledge protocols and guidance documents for research with Indigenous communities [108,116,118]. These also include strategies, priorities, and research policies produced by Indigenous governments and organizations [117,123]. Indigenous-focused documents were more likely to be produced by a national Indigenous organization, regional or local Indigenous government or land-claim organization, or a northern NGO (Figure 10). Regionally, a greater number of these documents were relevant to the NWT (Figure 10), but that reflects the diversity of First Nation, Métis, and Inuit populations in the territory. Among the three Inuit regions, it is interesting to note the higher number of Indigenous-focused documents in Nunavut. This may reflect the increased capacity in Nunavut to engage in research governance, where there are more local organizations producing research policies.

About $80 \%$ of all documents (88) included a discussion of Indigenous knowledge as a key source of understanding for northern environments and society, but only $25 \%$ (27) provided specific guidance on how to include or engage with Indigenous knowledge (Figure 11). These documents showed a wide range in their depth of discussion on Indigenous knowledge. In some cases, this is limited to a small mention of the impor- 
tance of including Indigenous knowledge, while others included an in-depth discussion of Indigenous knowledge in research or guidance on how to collect Indigenous knowledge.

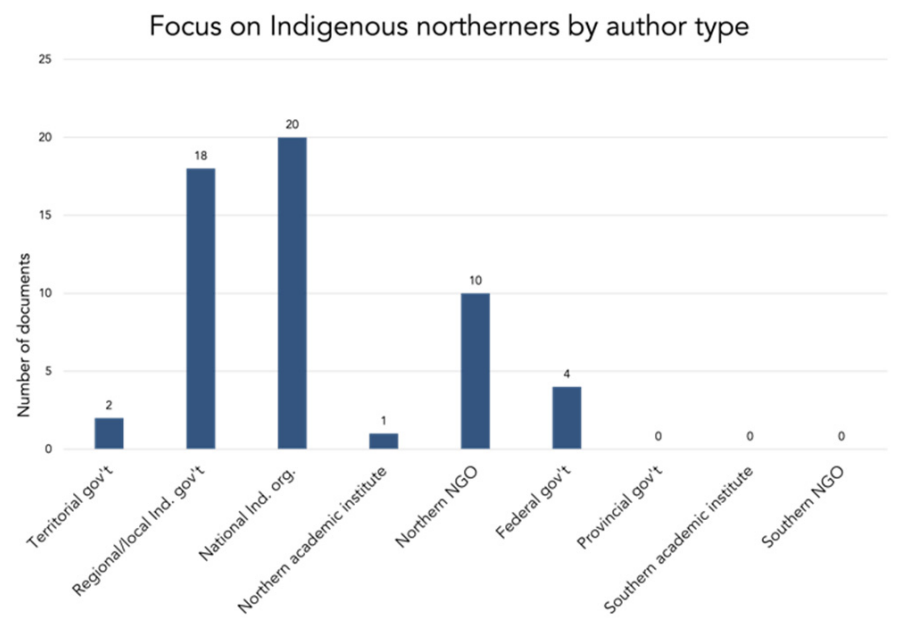

(a)

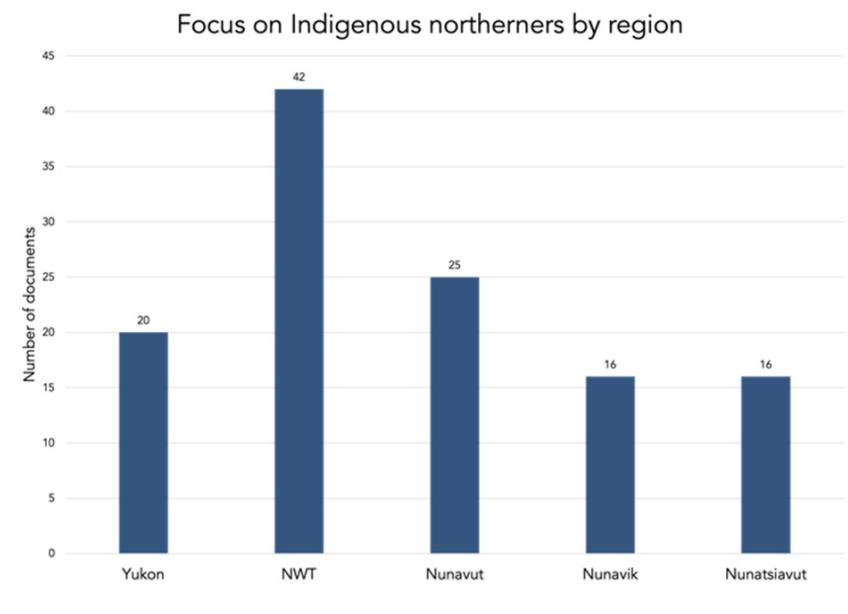

(b)

Figure 10. Inclusion of Indigenous northerners in document focus: (a) by author type; (b) by region.

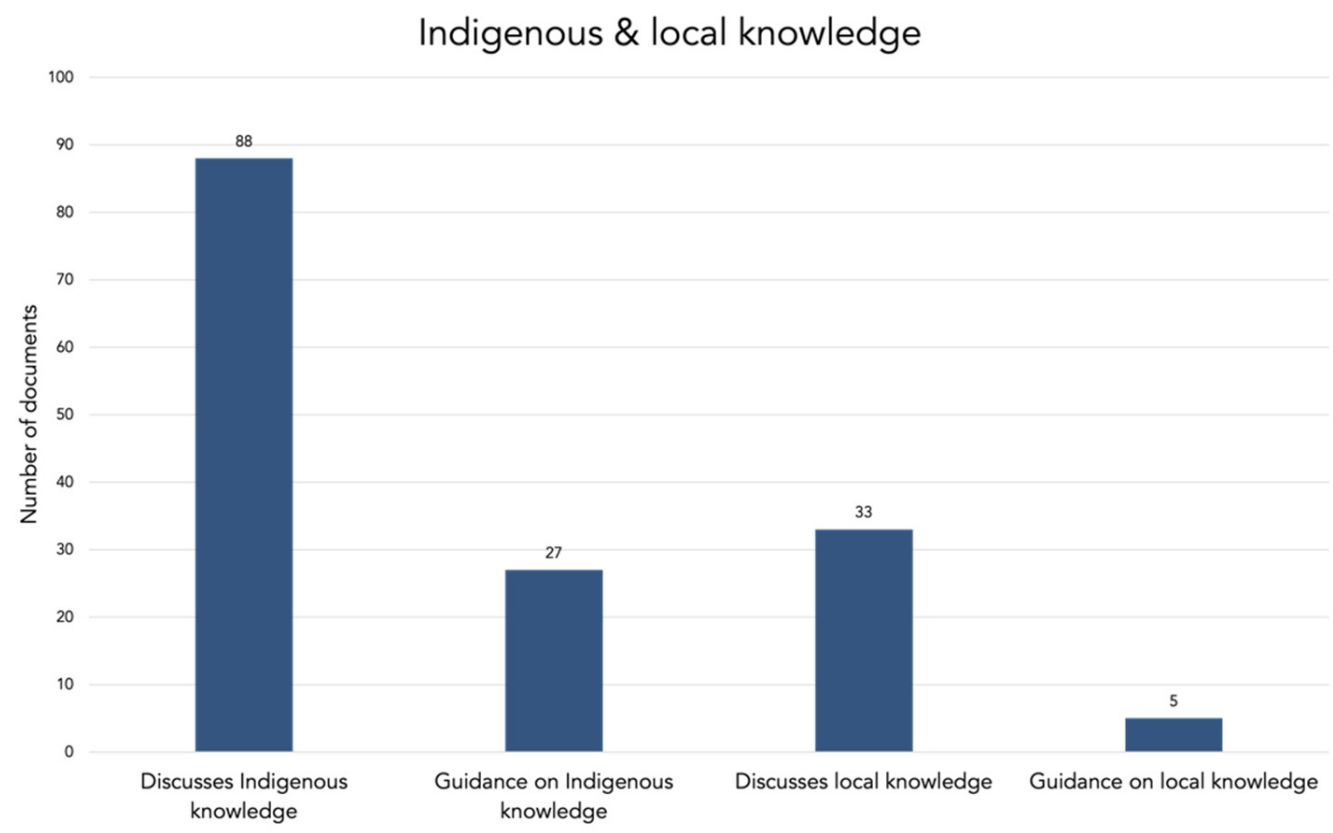

Figure 11. Documents with a main focus on Indigenous knowledge and local knowledge.

The 27 documents that provide guidance on Indigenous knowledge are produced by several different types of authors, including mainly regional and local Indigenous governments or land-claim organizations but also national Indigenous organizations and northern NGOs (Figure 12a). There are double the number of documents relevant to the Northwest Territories that provide guidance on Indigenous knowledge compared with the other regions (Figure 12b), again, reflective of the diversity of NWT's Indigenous population.

As well as being used as a document-level attribute to track how many documents referenced Indigenous knowledge, it was also one of the most applied codes in the thematic analysis. The code was only applied where Indigenous knowledge is discussed in depth, often with associated methodological and ethical considerations. Many northern organizations recognize that Indigenous knowledge and science come from different worldviews and should be considered in different ways. The language around Indigenous 
knowledge changes over time and varies between different organizations. Organizations that come from a western science tradition, particularly federal government departments, tend to discuss Indigenous knowledge as a data source that supports western science. In more recent publications, particularly those by Indigenous organizations and northern governments, the emphasis is placed on respecting Indigenous knowledge as a standalone knowledge system, as opposed to a source of data to be integrated with science [124]. Indigenous organizations emphasize that Indigenous knowledge is a knowledge system and worldview.

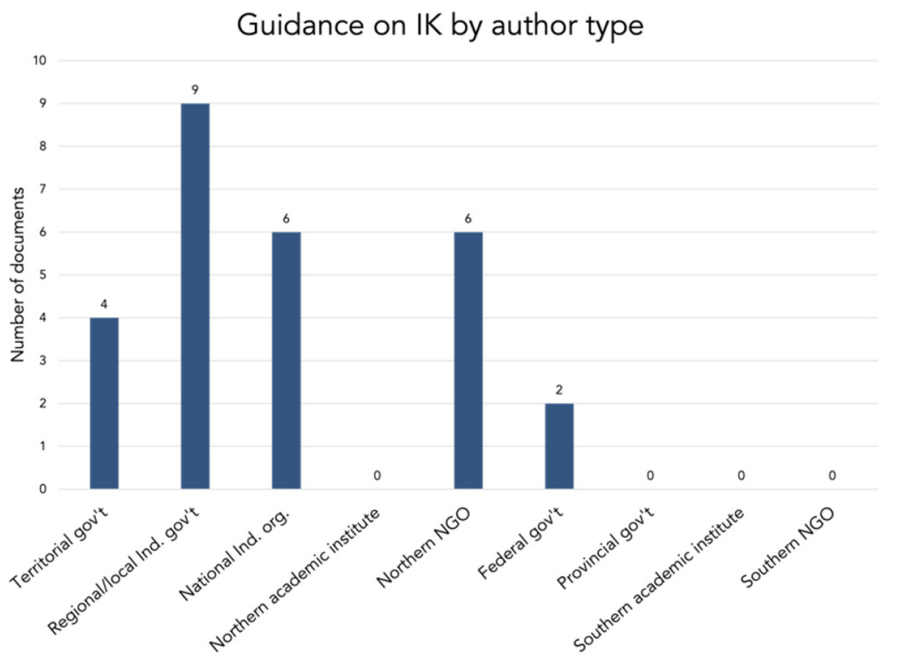

(a)

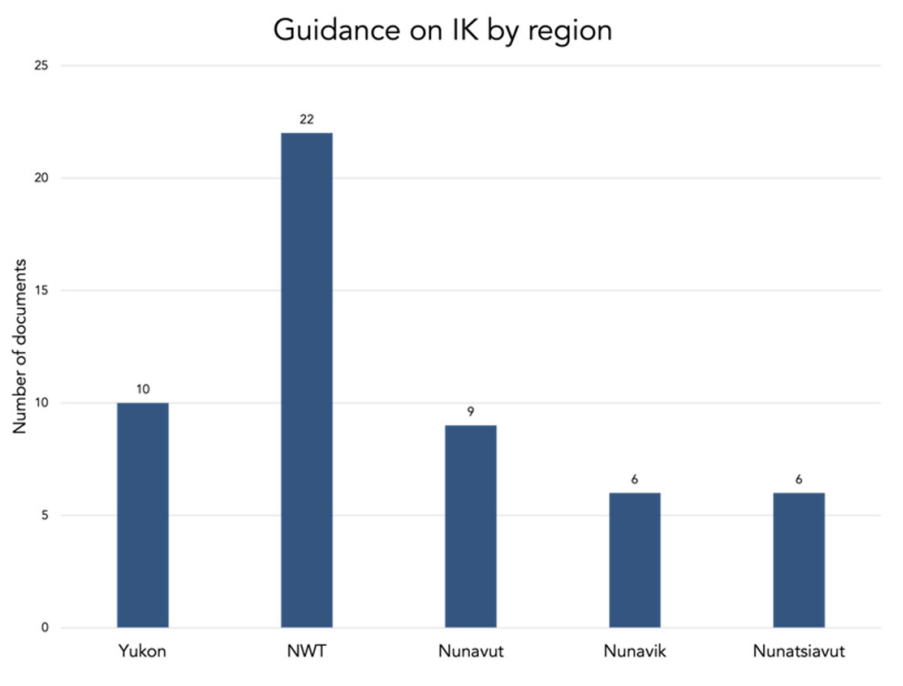

(b)

Figure 12. Guidance on Indigenous knowledge: (a) by author type; (b) by region.

Researchers often approach Indigenous knowledge as another form of topical knowledge that can inform research results and outputs. However, Indigenous knowledge should inform the start of the project, including how research is done, the principles and values that are incorporated in research design, and the relationship between the researcher and the community $[124,125]$. Some northern and Indigenous organizations advise researchers to recognize and include the interests and priorities of Indigenous northerners in the development of the project and to focus on a respectful, inclusive approach with Indigenous communities, as opposed to prioritizing the integration of Indigenous knowledge in scientific research $[104,125]$. As an example, the youth of Nunavut that are part of Ikaarvik: Barriers to Bridges highlight that Inuit Qaujimajatuqangit (IQ) is more than just knowledge. "IQ ... incorporates knowledge, customs and values. It is a way of life. It is as much about how we interact with one another, our attitudes and behaviours, as it is about what we know." [125]. This can also extend to ensuring that Indigenous interests and priorities are reflected in broader research policies, for example, in funding programs [4].

Indigenous knowledge was frequently cross-coded with informing policy decisions, indicating the value Indigenous knowledge can bring to the decision-making process. While there was some discussion of bridging Indigenous knowledge and science in designing and conducting research, bridging knowledge sources also comes up as a strategy for informing policy. This can be accomplished by bringing the two knowledge sources together at the decision-making level, as opposed to in an individual research project [104]. Concerns have been expressed that Indigenous knowledge collected by researchers may not result in practical applications, so approaches that ensure that Indigenous knowledge is available for use by Indigenous northerners would ensure that Indigenous knowledge is available for their policy needs [118]. For this to happen successfully, Indigenous knowledge needs to be valued as an equal source of evidence with scientific knowledge. Despite noted challenges in bringing together Indigenous knowledge and science, the Government 
of Canada has framed Canada as a leader and innovator in bridging Indigenous knowledge and science for evidence-based policy [77].

Data sharing and data ownership were widely used codes also cross-coded with Indigenous knowledge. This highlights the importance of OCAP and other data management frameworks for protecting the rights of Indigenous peoples to own and access their data and to control how it is used and communicated. As the Guidelines for Research with Yukon First Nations points out, "researchers have the ability to construct legitimate arguments for or against ideas, theories or practices. Researchers are collectors of information and producers of meaning, which can be used for, or against Yukon First Nations interests" [108]. There are numerous references to Indigenous knowledge or data being shared without permission or used for applications that were not approved. "Research has been damaging in the past in instances where genetic material is used, sensitive information is published and confidential cultural information is shared inappropriately" [126]. Northern research has been described as extractive, where data is used by researchers but not always returned to the community. "Communities have seen countless researchers come and go, taking samples and data to build their careers and leaving communities feeling used." [127]. In their guide to OCAP, the FNC-NAHO [112] highlights a few ways that Indigenous peoples have been wronged by research, as well as providing options for First Nations communities to apply OCAP principles to support self-determination.

Many organizations note the importance of Indigenous knowledge contributing to our understanding of key social, economic, and environmental sustainability topics in the North, including climate change, wildlife ecology, and well-being. In some cases, for community uptake of research, it is essential that Indigenous knowledge be considered in developing the project, particularly in identifying relevant research questions. "Inuit occasionally dismiss scientific studies (especially those on harvested wildlife species) as unnecessary and irrelevant where they believe the studies will provide knowledge that Inuit already possess" [83]. Indigenous knowledge was discussed as a key source of information for developing policy in relation to land and wildlife management, resource development, and environmental assessment. There is also interest in better understanding methodologies for incorporating Indigenous knowledge into management and planning processes. Sociocultural sustainability topics like language, traditions, and cultural practice are pannorthern priorities and are intrinsically linked with Indigenous knowledge. Language revitalization is a concern across the North, and while it can be the focus of research, it can also be integrated into research through use of Indigenous languages wherever possible.

\subsection{Research and Governance Capacity}

Within this thematic analysis, governance capacity refers to the leadership, oversight, and promotion of research, whereas research capacity is about having the capacity, whether it is tools, resources, infrastructure, expertise, personnel, skills, or other requirements, to engage in the practice of research, including conducting research, managing data, and implementing results in programs and policies $[110,128]$. Capacity building is not always a north-south relationship; it can happen within a region or across the North [30]. Capacity building is a partnership that requires efforts from both community and research partners and ultimately benefits both [110]. Research is often identified as a sector that requires funding and support to sustain ongoing activities, coordination, employment, and training opportunities for northerners and students. While the federal government has been a primary support for building local capacity by investing in colleges, research institutes, and infrastructure, there are still barriers to local research capacity and a need for support at the institutional, community, and individual scale in the North [48,127]. Funding, partnerships, support for human resources, technology, information and data management, assistance for proposal writing, and research-specific training can all contribute to both institutional and community research capacity $[65,112]$. Capacity to conduct research includes the need for adequate and sustainable research funding at the community level and for northern organizations and institutions to coordinate, contribute, and participate 
in research projects, networks, and partnerships, including infrastructure, equipment, or training as required $[38,104,115]$.

Capacity to conduct research and be involved in research is also intertwined with capacity to govern research. Where there is institutional capacity to engage in the oversight of research in the region and in research partnerships, there are more research opportunities for community members and organizations [38]. Involving northerners in research can contribute to both capacity to do research and capacity to use research; participating in research helps to develop skills, but it also helps build local understanding of an issue, which can help with applying the results [115]. Research that builds on existing capacity or community strengths is respectful of Indigenous values and contributes to meeting community needs $[65,110]$. Data governance was not only identified as a key concern, but it was also an area where Indigenous organizations have made big strides in asserting sovereignty by implementing OCAP or other data-ownership principles. Data management and ownership require the institutional capacity to apply the principles of OCAP [112,128]. Questioning the capacity of Indigenous and northern organizations when they assume control of research or data, instead of supporting their efforts, can interfere with northern leadership in research [112].

International partnerships also play a role in Canada's research capacity, particularly regarding emerging international priorities like climate change. In 2002, it was identified that Canadians were falling behind in research capacity, specifically in funding. Canadian researchers were reliant on their international partnerships to participate in international committees and projects [20]. International partnerships are still an important part of advancing northern scholarship and knowledge of northern systems, allowing Canadian researchers to share knowledge from other regions with northern Canada [77]. International collaboration can happen through research projects but also through formal partnerships, committees, or science associations [77]. Canada's participation in these international arenas depends on the support of the Canadian government [20]. IPY and the northern research chairs were successful examples of national funding to support northern research and foster international collaboration. POLAR and CHARS are examples of how the federal government is continuing to support this capacity. [48,76,77,129,130].

Governance capacity in northern research affects organizations at the local, regional, and national scale. For smaller organizations, this means identifying their limits in terms of support and partnership potential and prioritizing where to expend their resources [104]. Local governance usually includes organizational or advisory-group oversight of research. That can include reviewing research proposals, monitoring projects, and negotiating research relationships, as well as advocating for local priorities and interests [4]. Not all communities or local organizations have the capacity to provide this kind of oversight or have equivalent experience working with researchers [83,115]. Whether or not a community has a formal governance structure for research should not change how researchers approach the community. They should still consult with community leaders and organizations, providing similar opportunities for engagement. They may need to consider providing resources for the community to engage in the project.

At the regional level, territorial governments play multiple roles in governing research: leading and conducting research, developing partnerships, advocating for northern research priorities, influencing other organizations, and regulating research $[1,3,65]$. The ability to regulate research through licensing or permitting is a key component of governance capacity for the northern regions. However, to be effective, this system requires the active participation of community reviewers. More support for communities to engage in this would improve the licensing process, whether that is through community research advisors or other personnel $[38,131]$. The capacity of communities to review licensing applications can be affected by staff turnover and the loss of institutional knowledge.

Governance capacity is directly related to research sovereignty, or self-determination in research. When organizations have the capacity to engage in the oversight of research, they can directly influence the research agenda. As compared with funding for training, 
which supports the development of individual research capacity, support for organizations to engage in the oversight and governance of research can affect whether research meets local and regional needs [38]. Local research capacity is also intertwined with governance capacity, as funding for research capacity in the North relies on the advocacy of northern organizations. Governance capacity includes formal policies and strategies that commit funding for the participation of northerners and northern organizations in research oversight, without which research capacity can be vulnerable [20]. Governance capacity at the organizational level includes the ability to engage in research agreements and datamanagement agreements, which can require human resources, policy support, and data infrastructure [128]. This capacity ensures that community and regional-scale organizations can advocate for their research priorities and expectations and can implement OCAP and other data-management principles.

\subsection{Outcomes of Research}

A common expectation across different policy documents is that research should be relevant and have beneficial outcomes for the land, animals, and people in the North and provide specific contributions to the communities and regions where it takes place. Outcomes of research can include tangible benefits but can also include how local residents, organizations, and decision-makers can use the information produced or their experience with the research project.

"For Inuit, knowledge can only be described as such if it is used to improve the lives of others. If one has knowledge but does not share it or use it for the common good, then it is seen to have no value. In this light, all research must result in direct application to improving the lives of the people who contributed to the knowledge development. This understanding is critical to the design of all research being carried out with Inuit populations, but should be essential in all research anywhere." [106]

Researchers are recognized as experts who possess specialized skills and knowledge and who can help provide information for sound decision-making. Northern organizations and governments value research for the contribution it can make to local issues and northern society, particularly regarding environmental and sociocultural sustainability [108]. Research from all disciplines can contribute to decision-making; however, health and social science research in particular is expected to contribute to sustainability transformations $[4,7,132]$. Despite being identified as key priorities, health and social sciences, as well as humanities, have generally been underrepresented in northern research $[4,7,29,30,48,133]$. In Canada's Arctic and Northern Policy Framework, the Government of Canada [48] has recognized that need and committed to supporting more social science research.

Many northerners regard scientific research as a valuable tool to protect public wellbeing, generate wealth, and to advance knowledge for the benefit of communities and society at large. At the local scale, research can benefit communities by providing employment, training, equipment, contributions to local economy, and honoraria for participants $[30,134,135]$.

"Research provides much-needed capacity transfer between communities and researchers, opportunities for Indigenous peoples to address issues of local priority, and jobs that put food on the table for many families, and that can become pathways to educational and knowledge development opportunities and stable employment." [136]

However, there are also concerns that research can have adverse impacts on communities and the natural environment. Regulatory processes are in place across the North, including a research licensing process in the three territories and a research approval process in Nunatsiavut, to identify and mitigate potential negative impacts. A commitment to ethical approaches and communication with communities while designing research projects 
facilitates the pathway to positive outcomes and creates opportunities for northerners to engage with research projects.

\subsection{Informing Policies and Decisions}

The role of research in informing policies and decisions was a key theme that arose in the document analysis. Having scientific knowledge available for use in decision-making processes is a key priority, particularly in documents produced by territorial and federal governments, ITK, and regional or subregional Indigenous organizations (e.g., the IRC and CYFN). The code informing policy decisions was applied to two different aspects of research informing policy: (i) as a key step in the lifecycle of a research project (the act of sharing results to affect decisions or policies); and (ii) as an outcome of research (policy has been informed by research). With respect to policy as an outcome of research, there is a desire for research to contribute to social, health, and environmental solutions [2]. While research and science are recognized as important contributors to sustainability decisionmaking in the North, this is usually discussed in the documents as something that will happen in the future, as opposed to a current reality.

The prevalence of northern policy and decision-making as a theme in the analyzed documents highlights the importance of useable science in the North, which is also a key issue noted in the literature $[6,137,138]$. While all different types of organizations discuss the contributions research can make to policy and decision-making, the importance of research informing policy is particularly emphasized by Indigenous organizations that are involved in policymaking (e.g., ITK) and governments. However, little advice is given as to how this can be accomplished. There seems to be a common assumption that if research is based on local priorities, there will be uptake by policymakers. Yet, there is not always a causal link between relevant research and action or decision-making. Policy development incorporates a variety of information sources beyond academic research and science, and those can conflict with research results. Policymakers may require data at a different scale or format or may have identified different data gaps than researchers or communities. Participatory research methods are identified as a pathway to impact policy through inclusion of relevant decision-makers in the process. By including decision-makers early in the project, ideally in developing the project goals and research question, the hope is that research will be relevant to their needs and easily accessed.

The documents highlight the disparity between priorities at different scales, leaving gaps in the knowledge that is available and valued for decision-making.

"The next step in the evolution of scientific practice in the Arctic is linking community-driven Arctic research priorities with national policy development to ensure scientific investments benefit communities and answer key questions facing the Arctic. I firmly believe that the foundation of effective decision-making is good information. In the Arctic, that means being committed to placing equal value on Indigenous knowledge and western science." [119]

There is potential for tension between community needs and policy needs; however, open dialogue early in the project provides the opportunity to address these issues. Effective communication between research policymakers, funders, researchers, and research users can encourage the sharing of results for decision-making.

\subsection{Communication and Engagement}

Sharing knowledge is a dynamic process with knowledge flowing in multiple directions between researchers, knowledge holders, policymakers, community members, practitioners, and boundary organizations $[4,122,139]$. Relationships are the foundation of research in the North, and communication is part of building and maintaining relationships $[83,110]$. Consultation and engagement relate directly with the themes of communicating research and building research partnerships. Ensuring that research is relevant to the community or partner organization requires consulting with them on priorities and goals for the project. Consultation is not only encouraged; to a certain extent, it is mandated 
through permitting and licensing processes. Across the North, there are requirements for consulting with rightsholders regarding research; however, there are also examples of researchers not complying or ignoring those requirements. Local protocols, like Indigenous knowledge protocols $[116,140]$, also set expectations for engagement and communication. There is more of an obligation put on social science and health researchers to ensure their research is relevant, particularly as they are more likely to require local participation in their research [110]. However, research priorities for many northern organizations include natural and physical science topics that are relevant to community decision-making and can benefit from local consultation. For example, the GRRB has a list of priority wildlife topics that they recommend researchers engage with them on [123,141]. Researchers in all disciplines are also encouraged and expected to engage with the community before defining their research question to explore how the researcher's goals might align with the community's interests and needs. Early engagement and communication with communities will help researchers avoid initiating projects that the community is not interested in [127].

Although the onus is on the researcher to initiate communication with the community or relevant organizations, ongoing communication throughout a project requires commitment from all partners [114]. As an example, if the community clearly communicates their research expectations during preliminary engagement, there is less room for misunderstanding and conflict, and the project will be more likely to fulfill the community's needs [142]. Clear and ongoing communication was highly related to several of the steps in the lifecycle of a research project, including planning for a new project, identifying priorities and goals, defining questions, and reporting to communities and partners. For the Aqquimavvik Society, communicating research to the whole community starts while identifying goals and developing a shared understanding of the research project, which ultimately translates to informing local decision-making.

"This is also a time when all of this information is shared and promoted across the community so that there is a collective awareness of the issues and the process being proposed and that by sharing the background information, every community member is then able to consider the topic through the lens of personal experiences and ideas. In this way, the process of research is shared beyond those who are selected informants. This is an approach which seeks to raise critical consciousness across the community and build critical mass through engagement around the issues. It also sets the stage for meaningful knowledge translations of the data results." [106]

Clear communication using plain language and translation where needed is important for establishing an agreement and ensuring that everyone understands what will happen throughout the process.

Communities or local organizations can play a role in developing communication products, particularly in putting results in the broader context. An example is the Inuit Health Survey and the role NTI played in developing relevant communication products [27]. In cases where community members or organizations have directly contributed to the project, there may be an expectation that any reporting of results requires the consultation of local leadership and participants. "Sometimes researchers have published without consulting the community, resulting in negative consequences from publications where communities had no opportunity to correct misinformation or to challenge interpretations" [122]. Expectations for community input or control over the communication process might vary from project to project, depending on the relevance and importance of the topic for the community and the level of community involvement. Of utmost importance is identifying how and when results will be communicated and who has control over those decisions [112,128]. Community reporting is a key communication milestone and step in the research process that is reiterated throughout the documents analyzed.

In terms of when communication is essential within the research process, communication was highly related with the code identifying goals and priorities, which is a critical step for northern participation. When a community or partner organization has influence over 
research goals, the project is more likely to produce information that is useful locally. The next step in ensuring that results are used is sharing the data and results with interested communities and organizations in a format that is accessible and applicable. These two steps are essential for achieving research outcomes at the local scale. Recommendations for returning results to communities include sharing them through posters, community radio, pamphlets, and hosting a community presentation or open house $[83,143]$. Depending on the type of information being produced, there may also be a need to present key findings to local leadership for their feedback before publishing. Local governments or partner organizations may want a copy of the data and a report summarizing the project and key findings, particularly if there is relevance for policy. For example, the Gwich'in Tribal Council requests that researchers conducting Indigenous knowledge research present findings to the Chief and Council, the Renewable Resource Council and the Designated Gwich'in Organization while also encouraging researchers to present their findings to community members [144].

\section{Discussion}

Discussions of sustainability are intrinsically linked with how organizations communicate their desired outcomes of research. In discussing the need for and value of research, all different types of organizations conceptualize research as a contributor to environmental, sociocultural, and economic sustainability in the North. Both broad and focused sustainability priorities are identified across the policy documents included in this study. Although physical and natural science topics are a high priority in the North, there are opportunities for all disciplines to contribute to sustainability research. While northern research guidelines and policies are relevant to all research happening in the North, they are critical for sustainability research because of the importance of these issues for northerners. Sustainability research is often interdisciplinary, bringing together researchers from different methodological backgrounds and highlighting disciplinary divides in research approaches. Northern policies address some of those gaps by providing interdisciplinary guidance. The following section discusses key insights into how to align research with policy objectives to ensure research outcomes are relevant to the questions that northern governments and organizations are dealing with. We also bring together the expectations that northern organizations have for researchers as they engage in sustainability research and identify key avenues for academic research to support sustainability decision-making that is inclusive of northern values.

\subsection{Aligning Research with Northern Policy Objectives}

A key objective in conducting this research was to identify how research programs can align with northern science-policy objectives. With the pressure of growing sustainability issues in the North, finding ways to bridge research with policy is of utmost importance; however, there is a gap in identifying how that knowledge transfer occurs. Using research results to inform policy is usually identified as a step that happens at the end of a research project once the results are compiled and analyzed. However, by identifying potential users of research or policymakers at the beginning of the project and including them in key steps along the way, there is an opportunity to ensure the project can meet policy and program needs. Sustainability issues are often complex and multifaceted and can implicate several different organizations. Part of developing relevant projects is understanding the local context and local policy needs. Therefore, it is important to identify key groups in the community and region, such as organizations and decision-making bodies involved in the issue of concern. Engaging stakeholders that will be involved in incorporating results into decisions or programs during early stages of project development can promote knowledge transfer later in the project. This goes beyond tailoring communication products and includes designing a research question and methodology that are suitable for arriving at data and results that are relevant to policy. While this approach ensures policy priorities 
are considered at the outset, it needs to be done in a way that is respectful of the leadership and participation of local and Indigenous partners.

Some northern organizations, including the IRC, have recognized that if they want knowledge available to inform their decision-making and programs, they need to play an active role in setting the research agenda for their region [30]. While Arctic research plays an important role in addressing global and circumpolar sustainability issues, it should also support northern and Indigenous self-determination. This involves more than just providing knowledge to support local sustainability but also considerations around local consultation, ethical protocols, and accountability. For northern Indigenous governments and organizations, improving relationships and partnerships is intrinsically linked to their capacity to govern and influence the research agenda and process and, ultimately, selfdetermination in research $[4,5,36,112]$. There is strong support within both the academic and policy literature for sustainability research that is relevant and based on community priorities and goals $[13,14]$. Research that responds to community needs, respects local perspectives of sustainability, and incorporates community strengths can contribute to developing both policy and local research capacity. For researchers, ensuring that research is relevant to the community or partner organization requires consulting with them on priorities and goals for the project. Consultation is encouraged already in northern regions, and to a certain extent, it is mandated through permitting and licensing processes, but it mainly focuses on individual research projects and does not typically extend to policy relevance and governance organizations. Local protocols like Indigenous knowledge protocols set expectations for engagement and communication in research. However, such protocols must also be extended to developing respectful and meaningful policy that considers evidence based on Indigenous ways of knowing, values, and oral traditions.

Respecting northern leadership and self-determination requires careful consideration of how to include northern voices throughout research decision-making. There was a noticeable lack of documents at a community scale or subregional scale focusing on research policy broadly. Instead, those that did exist were focused on Indigenous knowledge, specific methodologies, or guidance on community-based research. This could reflect a lack of resources within those organizations and a need to focus on their immediate experiences with researchers. This puts an onus on the larger organizations that are producing policy documents to engage meaningfully with northern rightsholders and communities and effectively represent their input when putting forth broad northern research policies. It also indicates that there may be a need for resources to support smaller organizations and communities to engage in policy-setting exercises or to develop and communicate their sustainability research priorities to regional organizations and governments. The GRRB provides an example of how this can be done through their community consultations. On their website, they communicate both community research priorities that arise out of those consultations, as well as GRRB organizational research priorities. This process provides a voice for community members while also respecting that the GRRB has a specific mandate and research interests $[104,123,141]$.

\subsection{Expectations for Engagement in and Conduct of Research}

One of the objectives of this study was to understand how organizations expect researchers to engage in and conduct research. The process of developing and conducting research can be as important as the knowledge that is produced $[10,13,125]$. There are already ongoing conversations in both policy and scientific literature about the importance of participatory methodologies in northern research $[14,145,146]$, and there is guidance available on how to build relationships, engage in partnerships, and coproduce knowledge with northern communities $[11,13,57,147-152]$. These developments are not unique to the Canadian North, as similar conversations are happening in other jurisdictions, where policies and guidelines are being developed to address many of the same challenges [105,153-156]. Northern policy documents support the foundational concepts of relationship, partnership, and communication that underpin the development of relevant and applicable research. 
Although research relationships can be challenged by conflicting values, different worldviews, and competing needs and priorities, these challenges can be overcome by ongoing communication, shared goals, ethical approaches grounded in local needs, and formal research agreements $[110,122,128]$. The voices and perspectives of northerners are not necessarily reflected in the scientific or policy literature. However, participatory approaches and the coproduction of knowledge are approaches that have shown success in bringing these northern voices in. When these approaches are not suitable and other methodologies are being employed, an emphasis on relationships and communication with local partners can still result in useable research to inform sustainability decision-making. There is no single approach to participation that can be applied to all research projects; rather, there is a continuum of participation that can be implemented according to local needs $[83,146]$. Identifying where a project appropriately fits on that continuum comes from conversations with communities and local partners and requires dedication of appropriate time and resources for community and partner participation in project development. Local organizations may need financial or in-kind support for personnel to engage with researchers or resources to participate in priority-setting exercises.

Distrust of researchers is the result of past relationships where researchers were not accountable or did not provide tangible results $[1,4,27,127,157]$. Social license to conduct research is important in the northern context and comes from open communication and follow-through on commitments. Fulfilling the needs of both the community and the researcher can be a source of tension and is often negotiated through an ongoing dialogue. However, there may be research questions that are not addressed in some communities or regions because there is no social license to move forward. Yet, the North is not homogenous, and interest in different topics and methods may vary amongst communities and regions.

Expectations for research conduct are generally upheld by ethical-review processes or other regulatory processes; however, these can conflict with local and Indigenous protocols that value community (collective) consent, as well as the individual consent of participants [122,128]. Northern legislators and regulators support the community-consent process through the review of applications by local and regional organizations; however, without any capacity to enforce compliance, the process is not always accountable to communities $[4,122]$. Accountability mechanisms are often lacking and can undermine research relationships, programs, and ethical processes.

There is a long history of communities not receiving the results of research or of receiving a copy of a scientific publication that is not understandable or useful. When the community partners play a role in guiding and leading communications, there is more likely to be trust in and uptake of the research results. Communicating research is an iterative process that happens throughout a project, particularly if the goal is to influence policy. Communication with potential research users can create pathways for implementing research results in decision-making. Partner organizations with established relationships in the region may be better suited to communicating results than the researcher, effectively playing the role of a boundary organization by bridging science and policy through twoway communication [158]. This is particularly relevant when communicating sensitive information or Indigenous knowledge, which may require contextualization by community members or partners.

\subsection{Supporting Sustainability Decision-Making}

The final objective was to identify avenues for academic research to support policy and decision-making related to sustainability. Northern research is expected to directly impact local decision-making, supporting sustainability transformations in resource development, wildlife management, healthy communities, cultural revitalization, and economic development, among other issues $[1,2,148]$. Incorporating northern voices, context, and values in developing priorities and goals related to sustainability research is essential to approaching sustainability in a way that is relevant and potentially transformational $[86,149]$. Sustain- 
ability transformation requires local context and input; coproduction and participatory methodologies can support the incorporation of local perceptions of sustainability $[90,149]$. An example of this is Inuit Qaujimajatuqangit, which has sustainability principles embedded within Inuit societal values, particularly the principle of avatimik kamattiarniq, which "encourages sustainable social/environmental stewardship" [124]. Although the term coproduction was not widely used in the analyzed policy documents, many of the principles of knowledge coproduction were discussed throughout, highlighting that while northern organizations may be slower to adopt the term than the research community, the process itself is important. Self-government and self-determination can support the capacity for Indigenous northerners to engage in sustainability research and to apply the results within their own decision-making organizations [8,150].

Within the broad sustainability priorities discussed throughout the policy documents, variability exists between regions and communities regarding specific research priorities and questions. Overwhelmingly, environmental sustainability is discussed throughout the analyzed documents as a key concern for northern regions and as an expected outcome of northern research. Climate change and resource development are the two major threats discussed in relation to northern environmental sustainability, and climate change is identified as "arguably the single greatest challenge facing the Arctic and its residents" [57]. Social and economic sustainability priorities in the North also include issues like language revitalization and preservation, cultural heritage, mental health and suicide prevention, impacts of residential schools, healthy lifestyles, economic opportunities, and the impacts of tourism and other economies $[1,57,66,77,91,113,151,159]$. While some sustainability topics that have global significance may not appear to be a local priority, through thoughtful communication and consultation, they may garner local interest. There are countless sustainability research gaps with local relevance and scientific significance.

Research on climate change is noted as a community, regional, and circumpolar issue, yet it is discussed in different ways by different author types. Although climate change, broadly, is a shared priority, there are divergent priorities between different types of organizations. For territorial governments, Indigenous governments, and ITK, climate-change research provides information that can improve local decision-making. The Government of Canada has obligations to both the northern regions and to circumpolar science, which is reflected in their discussion of climate-change priorities. They identify the importance of advancing global knowledge and scholarship of climate change while also acknowledging the importance of contributing to local knowledge of climate change for solving sustainability issues [20]. Priorities at the community scale, as identified by northern NGOs, northern Indigenous governments and organizations, territorial governments, and ITK, include how climate change and resource development impact the land, wildlife, and community well-being in their region. Their priorities are to identify local solutions and adaptations to support sustainability, emphasizing the critical need for climate-change research to be relevant and contribute to local decision-making. Climate change and resource development at the local scale are discussed as cross-cutting issues that impact sociocultural and economic sustainability, as well as environmental sustainability, with wide-ranging impacts on cultural activities, food security, community well-being, and traditional and resource economies, among others $[57,81,113,152,159,160]$.

\section{Conclusions}

This examination of northern research-policy documents from across Canada emphasizes the critical importance of sustainability research in addressing policy and decisionmaking priorities identified by a broad range of organizations. While there are overarching issues commonly identified across the North, local interests can vary greatly, as can local perspectives on what sustainability entails. Understanding and responding to this diversity are important aspects of addressing local needs. Our analysis serves to highlight the importance of coproduction and participatory approaches in aligning sustainability research and policy. We also articulate the impact that including policy and decision-making 
organizations can have on creating a pathway from research to evidence-informed policy. Ultimately the policy documents analyzed emphasize the need for sustainability research to be conducted in a way that is attentive to the research process, regardless of methodology, including accountable partnerships, institutional and community ethics, and clear and open communication.

Although the need for research that is inclusive of northerners, focuses on northern priorities, and is led and conducted by northerners has been recognized for years, the most recently produced policy documents and current academic literature still discuss challenges and gaps with research meeting specific northern needs. Although in many ways, northern sustainability research has advanced the coproduction of knowledge, northern organizations continue to focus their limited resources on advocating for better research practices, indicating that there are ongoing issues. Arising from our policy analysis are five key recommendations that can support both researchers and northern and Indigenous organizations to strengthen the research-policy interface for Arctic sustainability:

1. Develop multiscale, inclusive research partnerships-Research partnerships can be improved at both the individual and organizational scales to focus on northern sustainability priorities. This involves being inclusive of northern leadership, recognizing northern conceptualizations of sustainability, and ensuring benefits for northerners. Better partnerships with individual researchers result in improved projects and initiatives; however, organizational-scale partnerships (e.g., Indigenous or territorial government to university) have the potential to influence research agendas and improve research across multiple projects. The value of multiscale research partnerships has been recognized for some time; however, they can require considerable investments in personnel and financial capacity by all or some of the partners. When accompanied by policy directives, these investments can be impactful.

2. Ensure distributed benefits-To ensure that the benefits of sustainability research are distributed across the North, both larger partner organizations and individual researchers need to consider how they can contribute to local research capacity and where their research could have the most impact. Some communities may be overburdened with research, while others do not benefit because they are lacking capacity to attract and engage researchers. Ensuring that benefits reach underserved communities or organizations may require more time invested in building relationships and more financial support for local participation.

3. Develop dynamic, tailored communications for different audiences-Policy documents can be an effective means to communicate an organization's research interests; however, they need to be tailored to the appropriate audience. The messages must be clear, concise, and avoid jargon. While sustainability issues are often complex and persistent, local priorities may change regularly. This type of information needs to be updated regularly and can best be communicated through a website, as opposed to a static report. Developing communication materials and policy documents can require dedicated staff or external support.

4. Expand on research guidance related to policy contributions-There are numerous documents already available that provide research guidance and several established ethical and permitting processes for research. Organizations considering creating their own research guidance are encouraged to consider how they can fill gaps in existing guidance documents and avoid duplication of existing advice. Useful additions would be organizational-specific advice on connecting research with policy priorities, including clear guidance on how, when, and who to approach at a specific organization. Articulating specific policy and research interests or priorities can also help to attract relevant research partners. This requires time and human resources on the part of the organization; however, it can minimize duplication and maximize effort in developing tailored guidance where needed.

5. Create more inclusive and accountable processes-Organizations that have the resources to develop and communicate broad research policies can create more inclusive 
processes to ensure transparency and accountability in how they include and represent Indigenous and community voices. Northern voices have been included in both scientific and policy literature in the past; however, their interests are usually communicated through the lens of the authoring organization. Crediting all contributors, including direct quotes, articulating and respecting Indigenous values, and developing more creative approaches to communicating guidance or policy-relevant findings (e.g., artistic graphics, short, plain-language text with appropriate translation, videos, podcasts, etc.) can help to enhance inclusion and accountability. Supporting the inclusion of smaller organizations and community members in policy development will require dedicated funding for their time to contribute. It also requires openness and transparency in ensuring that the input of contributors is clearly communicated and attributed.

While systematic reviews provide insight into research findings from peer-reviewed literature, they rarely capture research or science policies in the grey literature (e.g., government documents, NGO and Indigenous reports and policies). Research-policy documents are an avenue for northern organizations and governments to communicate their research goals and priorities and advocate for research that responds to their needs and contributes to Arctic sustainability. Policy documents provide insight into the motivations of organizations that are actively involved in guiding, legislating, and conducting research. This study provides unique insight into the policy context of northern research, examining issues from the lens of different types of organizations. Although this study did not examine funding-program documentation, our review does demonstrate the influence of funding programs in shaping how research is governed and conducted. Future research into the funding landscape could help to expand our understanding of the role funding plays in linking research policy with how research is conducted. Relationships, partnership, and communication are the foundation of relevant and applicable research, and our analysis shows that these are also essential in ensuring research can inform sustainability policy and decision-making. Policy applications must be considered at the outset of a research project, while ensuring inclusive and accountable research processes throughout, to present evidence that is meaningful in northern and Indigenous contexts. While common sustainability issues were shared amongst the organizations, addressing diverse perspectives and priorities in different regions and at different scales means that sustainability research needs to be embedded in local needs and perspectives. Ultimately, aligning northern research programs and science-policy objectives requires dedicated time and resources for communication and engagement.

Supplementary Materials: The following are available online at https:/ /www.mdpi.com/article/ 10.3390/su132112035/s1, Table S1: Details of policy documents analyzed.

Author Contributions: A.D.P.: concept, methodology, analysis, and writing; G.L.: academic supervision, contributions to concept development, review methodology, thematic code structure, paper review and editing; A.O.: contributions to concept development, paper review, and editing. All authors have read and agreed to the published version of the manuscript.

Funding: This research was funded by a doctoral scholarship granted by the Social Sciences and Humanities Research Council (SSHRC) and graduate student funding from the Government of Yukon.

Data Availability Statement: The data supporting the reported results in the present study will be available on request from the corresponding author or the first author.

Acknowledgments: In developing this research project, we held preliminary planning consultations with numerous organizations across the North, which provided initial direction for this paper. We would like to thank representatives of Tr'ondëk Hwëch'in First Nation, Selkirk First Nation, Arctic Institute of Community-Based Research, Council of Yukon First Nations, Wildlife Management Advisory CouncilNorth Slope, Yukon University, Arctic Institute of North America, Yukon Government, Gwich'in Renewable Resources Board, Inuvialuit Regional Corporation, Joint Secretariat - Inuvialuit Settlement Region, NWT Association of Communities, Aurora Research Institute, Government of the Northwest 
Territories, Qaujigiartiit Health Research Centre, Nunavut Tunngavik Inc., Nunavut Research Institute, Government of Nunavut, Makivik Corporation, Inuit Tapiriit Kanatami, Crown-Indigenous Relations and Northern Affairs Canada, and Polar Knowledge Canada. We would like to thank Chris Burn for his feedback on an early draft of this paper, Stephanie Sahl for assistance in creating the map of northern regions, and the students of the StraightUpNorth research group (https:/ / straightupnorth.ca) for their advice and feedback during paper development. We would like to thank the three anonymous reviewers whose thoughtful comments helped us improve this article.

Conflicts of Interest: The authors declare no conflict of interest.

\section{Appendix A. Coding Framework}

Table A1. Coding framework.

\begin{tabular}{|c|c|c|}
\hline Coding Topics & Parent Codes & Sub-Codes \\
\hline \multirow{9}{*}{ Research concepts } & Capacity building & $\begin{array}{l}\text { Compliance capacity; Cultural competency; Funding stability; Governance } \\
\text { capacity; Research capacity; Review capacity; Training }\end{array}$ \\
\hline & $\begin{array}{l}\text { Communication } \\
\text { and engagement }\end{array}$ & $\begin{array}{c}\text { Authorship; Clear communication; Consultation-engagement; Language; } \\
\text { Local hiring; Local knowledge; Methods of community engagement }{ }^{1} \text {; } \\
\text { Oral history; Plain language; Translation }\end{array}$ \\
\hline & Context & $\begin{array}{c}\text { Academic standards }{ }^{1} \text {; Advance northern scholarship; Colonial history of } \\
\text { research; Community ignored }{ }^{1} \text {; Cross-cultural context; Increase/decrease in } \\
\text { research; Interdisciplinary; Knowledge network; New research paradigm; } \\
\text { Research agenda }\end{array}$ \\
\hline & Definitions & $\begin{array}{c}\text { Definition community; Definition data; Definition Indigenous knowledge; } \\
\text { Definition north/Arctic }{ }^{1}\end{array}$ \\
\hline & Ethical protocols & Informed consent; Local approval; Local protocol; Withdrawing from research ${ }^{1}$ \\
\hline & Indigenous knowledge (IK) & $\begin{array}{c}\text { Documenting IK; Generational knowledge }{ }^{1} \text {; Indigenous research } \\
\text { methodologies; Indigenous worldviews; Integrating IK \& science; Sacred } \\
\text { knowledge; Traditions }{ }^{1}\end{array}$ \\
\hline & Research outcomes & Impact of research; Research benefits; Sustainability ${ }^{1}$ \\
\hline & Partnership & $\begin{array}{c}\text { Accountability; Building relationships; Co-developing }{ }^{1} \text {; Community needs }{ }^{1} \text {; } \\
\text { Northern participation; Research agreement; Research network; Researcher } \\
\text { needs }{ }^{1} \text {; Respect; Understanding }\end{array}$ \\
\hline & Place & $\begin{array}{c}\text { Culture camp; Land claims; Mapping; Research burden; Traditional } \\
\text { homelands-territories; Traditional place names }\end{array}$ \\
\hline \multirow{7}{*}{ Research lifecycle } & Research process & \\
\hline & Research planning & $\begin{array}{l}\text { Identify funding; Identify project priorities \& goals; Preliminary engagement; } \\
\text { Recruit project team }\end{array}$ \\
\hline & Research design & $\begin{array}{l}\text { Choose methodology; Create timeline; Develop research question; Identify } \\
\text { resource requirements; Literature-information search; Write proposal; } \\
\text { Proposal review }\end{array}$ \\
\hline & Preparing for research & $\begin{array}{c}\text { Acquire permits; Acquire research license; Ethical review process; Gain local } \\
\text { context; Gain local permissions; Plan logistics }\end{array}$ \\
\hline & Conducting research & $\begin{array}{l}\text { Analyze data; Collect data \& information; Compliance requirements; } \\
\text { Recording information; Storing data; Validate results }\end{array}$ \\
\hline & Communicating research & Community reporting; Publications; Reporting; Sharing data; Writing results \\
\hline & Implementing research & Evaluation; informing policy-decision \\
\hline Research roles & & $\begin{array}{c}\text { Advisor-mentor; Boundary organization }{ }^{1} \text {; Community; Coordinator; Elder; } \\
\text { Funder; Guide; Legislator-regulator; Local researcher; Participant; Partner } \\
\text { organization; Principal investigator; Researcher; Reviewer; Student; Support } \\
\text { staff-organization; Team member; Translator; User-consumer; } \\
\text { Videographer-photographer; Youth }\end{array}$ \\
\hline
\end{tabular}

${ }^{1}$ Emergent code. 


\section{References}

1. Government of the Northwest Territories. Knowledge Agenda: Northern Research for Northern Priorities; Government of the Northwest Territories: Yellowknife, NT, Canada, 2017.

2. Government of Yukon; Government of the Northwest Territories; Government of Nunavut. A Pan-Northern Approach to Science; Government of Yukon; Government of the Northwest Territories; Government of Nunavut: Whitehorse, YT, Canada; Yellowknife, NT, Canada; Iqaluit, NU, Canada, 2016.

3. Government of Yukon. Science Strategy; Government of Yukon: Whitehorse, YT, Canada, 2016.

4. Inuit Tapiriit Kanatami. National Inuit Strategy on Research; Inuit Tapiriit Kanatami: Ottawa, ON, Canada, 2018.

5. Brunet, N.D.; Hickey, G.M.; Humphries, M.M. Local Participation and Partnership Development in Canada's Arctic Research: Challenges and Opportunities in an Age of Empowerment and Self-Determination. Polar Rec. 2016, 52, 345-359. [CrossRef]

6. Ogden, A.E.; Schmidt, M.; van Dijken, B.; Kinnear, L. Science in the Yukon: Advancing a Vision for Evidence-Based Decision Making. Arctic 2016, 69, 210-221. [CrossRef]

7. Petrov, A.N.; BurnSilver, S.; Chapin, F.S.; Fondahl, G.; Graybill, J.; Keil, K.; Nilsson, A.E.; Riedlsperger, R.; Schweitzer, P. Arctic Sustainability Research: Toward a New Agenda. Polar Geogr. 2016, 39, 165-178. [CrossRef]

8. Riedlsperger, R.; Goldhar, C.; Sheldon, T.; Bell, T. Meaning and means of "sustainability": An example from the Inuit settlement region of Nunatsiavut, Northern Labrador. In Northern Sustainabilities: Understanding and Addressing Change in the Circumpolar world; Fondahl, G., Wilson, G.N., Eds.; Springer International: Cham, Switzerland, 2017; pp. 317-336, ISBN 9783319461502.

9. Fondahl, G.; Wilson, G.N. Exploring sustainabilities in the circumpolar North. In Northern sustainabilities: Understanding and Addressing Change in the Circumpolar World; Fondahl, G., Wilson, G.N., Eds.; Springer International: Cham, Switzerland, 2017; pp. 1-12, ISBN 9783319461502.

10. Gearheard, S.F.; Shirley, J. Challenges in Community-Research Relationships: Learning from Natural Science in Nunavut. Arctic 2007, 60, 62-74. [CrossRef]

11. Tondu, J.M.E.; Balasubramaniam, A.M.; Chavarie, L.; Gantner, N.; Knopp, J.A.; Provencher, J.F.; Wong, P.B.Y.; Simmons, D. Working with Northern Communities to Build Collaborative Research Partnerships: Perspectives from Early Career Researchers. Arctic 2014, 67, 419-429. [CrossRef]

12. Brunet, N.D.; Hickey, G.M.; Humphries, M.M. Understanding Community-Researcher Partnerships in the Natural Sciences: A Case Study from the Arctic. J. Rural Stud. 2014, 36, 247-261. [CrossRef]

13. Wilson, K.J.; Bell, T.; Arreak, A.; Koonoo, B.; Angnatsiak, D.; Ljubicic, G.J. Changing the Role of Non-Indigenous Research Partners in Practice to Support Inuit Self-Determination in Research. Arct. Sci. 2020, 6, 127-153. [CrossRef]

14. Carter, N.A.; Dawson, J.; Simonee, N.; Tagalik, S.; Ljubicic, G.J. Lessons Learned through Research Partnership and Capacity Enhancement in Inuit Nunangat. Arctic 2019, 72, 381-403. [CrossRef]

15. England, J.H.; Dyke, A.S.; Henry, G.H.R. Canada's Crisis in Arctic Science: The Urgent Need for an Arctic Science and Technology Policy; or, "Why Work in the Arctic? No One Lives There". Arctic 1998, 51, 183-197. [CrossRef]

16. Hik, D.S. A Northern Science Policy for Canada. In Proceedings of the 2030 North: A National Planning Conference, Ottawa, ON, Canada, 1-4 June 2009. Paper 4.

17. Korsmo, F.L.; Graham, A. Research in the North American North: Action and Reaction. Arctic 2002, 55, 319-328. [CrossRef]

18. Morris, D.W.; Beaulieu, M.; Hamilton, S.; Hik, D.S.; Lemelin, R.H.; Moses, M.M.; Müller, D.K.; Smith, M.A.; Smol, J.P. The Lakehead Manifesto: Principles for Research and Development in the North. Arctic 2013, 66, iii-iv. [CrossRef]

19. Pigford, A.E.; Hickey, G.M.; Klerkx, L. Towards Innovation (Eco)Systems: Enhancing the Public Value of Scientific Research in the Canadian Arctic. In Arctic Yearbook; 2017; Arctic Portal: Akureyri, Iceland; pp. 1-28.

20. Natural Sciences and Engineering Research Council of Canada; Social Sciences and Humanities Research Council of Canada. From Crisis to Opportunity: Rebuilding Canada's Role in Northern Research; Natural Sciences and Engineering Research Council of Canada; Social Sciences and Humanities Research Council of Canada: Ottawa, ON, Canada, 2000.

21. Castleden, H.E.; Morgan, V.S.; Lamb, C. "I Spent the First Year Drinking Tea": Exploring Canadian University Researchers” Perspectives on Community-Based Participatory Research Involving Indigenous Peoples. Can. Geogr. Géographe Can. 2012, 56, 160-179. [CrossRef]

22. McGregor, D.; Bayha, W.; Simmons, D. "Our Responsibility to Keep the Land Alive": Voices of Northern Indigenous Researchers. Pimatisiwin J. Aborig. Indig. Community Health 2010, 8, 101-124.

23. Yukon Native Brotherhood. Together Today for Our Children Tomorrow: A Statement of Grievances and an Approach to Settlement by the Yukon Indian People; Council for Yukon Indians: Whitehorse, YT, Canada, 1973.

24. Castleden, H.E.; Mulrennan, M.E.; Godlewska, A. Community-Based Participatory Research Involving Indigenous Peoples in Canadian Geography: Progress? An Editorial Introduction. Can. Geogr. Géographe Can. 2012, 56, 155-159. [CrossRef]

25. Ford, J.D.; Couture, N.; Bell, T.; Clark, D.G. Climate Change and Canada's North Coast: Research Trends, Progress, and Future Directions. Environ. Rev. 2017, 26, 82-92. [CrossRef]

26. Martello, M.L. Global Change Science and the Arctic Citizen. Sci. Public Policy 2004, 31, 107-115. [CrossRef]

27. Nunavut Tunngavik Inc. Annual Report on the State of Inuit Culture and Society 2011-2013; Nunavut Tunngavik Inc: Iqaluit, NU, Canada, 2013.

28. Wong, C.; Ballegooyen, K.; Ignace, L.; Johnson, M.J.; Swanson, H. Towards Reconciliation: 10 Calls to Action to Natural Scientists Working in Canada. Facets 2020, 5, 769-783. [CrossRef] 
29. Association of Canadian Universities for Northern Studies. Research Excellence in Yukon: Increasing Capacity and Benefits to Yukoners in the Social Sciences, Humanities and Health Sciences; Association of Canadian Universities for Northern Studies: Ottawa, ON, Canada, 2017.

30. Association of Canadian Universities for Northern Studies. Research Excellence in the Northwest Territories: Holistic, Relevant and Ethical Research in the Social Sciences, Humanities and Health Sciences; Association of Canadian Universities for Northern Studies: Ottawa, ON, Canada, 2018.

31. Pedersen, C.; Otokiak, M.; Koonoo, I.; Milton, J.; Maktar, E.; Anaviapik, A.; Milton, M.; Porter, G.; Scott, A.; Newman, C.; et al. ScIQ: An Invitation and Recommendations to Combine Science and Inuit Qaujimajatuqangit for Meaningful Engagement of Inuit Communities in Research. Arct. Sci. 2020, 339, 1-14. [CrossRef]

32. Mearns, R. Nunavut, Uqausivut, Piqqusivullu Najuqsittiarlavu (Caring for Our Land, Language and Culture): The Use of Land Camps in Inuit Knowledge Renewal and Research. Master's Thesis, Carleton University, Ottawa, ON, Canada, 2017.

33. Sudlovenick, E. A Serological Survey and Inuit Qaujimajatuqangit of Ringed Seals (Nattiit) in Frobisher Bay, Nunavut; University of Prince Edward Island: Charlottetown, PE, Canada, 2019.

34. Price, J. Tukisivallialiqtakka: The Things I Have Now Begun to Understand: Inuit Governance, Nunavut and the Kitchen Consultation Model; University of Victoria: Victoria, BC, Canada, 2007.

35. Karetak, J.; Tester, F.; Tagalik, S. (Eds.) Inuit Qaujimajatuqangit: What Inuit Have Always Known to Be True; Fernwood Publishing: Halifax, NS, Canada; Winnipeg, MN, Canada, 2017.

36. Snook, J.; Cunsolo, A.; Dale, A. Co-Management Led Research and Sharing Space on the Pathway to Inuit Self-Determination in Research. North. Public Aff. 2018, 6, 52-56.

37. Moffitt, M.; Chetwynd, C.; Todd, Z. Interrupting the Northern Research Industry: Why Northern Research Should be in Northern Hands. North. Public Aff. 2016, 4, 32-37.

38. Inuit Tapiriit Kanatami; Inuit Circumpolar Council Canada. Building Inuit Nunaat: The Inuit Action Plan; Inuit Tapiriit Kanatami; Inuit Circumpolar Council Canada: Ottawa, ON, Canada, 2007.

39. Grimwood, B.S.R.; Cuerrier, A.; Doubleday, N.C. Arctic Community Engagement during the 2007-2008 International Polar Year. Polar Geogr. 2012, 35, 189-193. [CrossRef]

40. Pulsifer, P.L.; Gearheard, S.F.; Huntington, H.P.; Parsons, M.A.; McNeave, C.; McCann, H.S. The Role of Data Management in Engaging Communities in Arctic Research: Overview of the Exchange for Local Observations and Knowledge of the Arctic (ELOKA). Polar Geogr. 2012, 35, 271-290. [CrossRef]

41. Gearheard, S.F.; Aporta, C.; Aipellee, G.; O'Keefe, K. The Igliniit Project: Inuit Hunters Document Life on the Trail to Map and Monitor Arctic Change. Can. Geogr. 2011, 55, 42-55. [CrossRef]

42. Kulkarni, T.; Watkins, J.M.; Nickels, S.; Lemmen, D.S. Canadian International Polar Year (2007-2008): An Introduction. Clim. Change 2012, 1-11. [CrossRef]

43. Hovelsrud, G.K.; Krupnik, I. IPY 2007-08 and Social/Human Sciences: An Update. Arctic 2007, 59, 341-348. [CrossRef]

44. Bone, R.M. The Canadian North: Issues and Challenges, 5th ed.; Oxford University Press: Don Mills, ON, Canada, 2016.

45. Abele, F.; Courchene, T.J.; Seidle, F.L.; St-Hillaire, F. (Eds.) Northern Exposure: Peoples, Powers, and Prospects in Canada's North; Institute for Research on Public Policy: Montreal, QC, Canada, 2009.

46. Dacks, G. Implementing First Nations Self-Government in Yukon: Lessons for Canada. Can. J. Polit. Sci. 2004, 37, 671-694. [CrossRef]

47. Government of Canada. Northwest Territories Lands and Resources Devolution Agreement; Government of Canada: Ottawa, ON, Canada, 2013.

48. Government of Canada. Canada's Arctic and Northern Policy Framework. Available online: https://www.rcaanc-cirnac.gc.ca/ eng/1560523306861/1560523330587 (accessed on 15 January 2020).

49. Higginbotham, J.; Spence, J. (Eds.) North of 60: Toward a Renewed Canadian Arctic Agenda; Centre for International Governance Innovation: Waterloo, ON, Canada, 2016.

50. Larsen, J.N.; Fondahl, G. (Eds.) Arctic Human Development Report: Regional Processes and Global Linkages; Nordic Council of Ministers: Copenhagen, Denmark, 2014; ISBN 9789289338813.

51. Rudolph, A.N. Breaking down Colonial Borders in Inuit Nunaat through Education; The Gordon Foundation: Toronto, ON, Canada, 2017.

52. Truth and Reconciliation Commission. Canada's Residential Schools: The Inuit and Northern Experience; McGill-Queen's University Press: Montreal, QC, Canada; Kingston, ON, Canada „, 2015.

53. Petrov, A.N. Re-Tracing Development Paths: Exploring the Origins and Nature of the 20th Century's Northern Development Paradigms in Russia and Canada. In Arctic Yearbook; 2018; Arctic Portal: Akureyri, Iceland; p. 21.

54. Simon, M. Inuit and the Canadian Arctic: Sovereignty Begins at Home. J. Can. Stud. Détudes Can. 2009, 43, 250-260. [CrossRef]

55. Wilson, G.N. Nunavik and the Multiple Dimensions of Inuit Governance. Am. Rev. Can. Stud. 2017, 47, 148-161. [CrossRef]

56. Jeffrey, A.; Fiser, A.; Brender, N.; Dowdall, B. Building a Resilient and Prosperous North: Centre for the North Five-Year Compendium Report; Conference Board of Canada: Ottawa, ON, Canada, 2015.

57. Special Senate Committee on the Arctic. Northern Lights: A Wake-up Call for the Future of Canada; Senate of Canada: Ottawa, ON, Canada, 2019.

58. Ogden, A.E.; Thomas, M.-E. Re: The Lakehead Manifesto. Arctic 2013, 66, 508. [CrossRef] 
59. Ile Royale Enterprises Ltd. The Canadian Network of Northern Research Operators Strategic Plan 2016-2021; Ile Royale Enterprises Ltd: Yellowknife, NT, Canada, 2016.

60. Council of Yukon First Nations. History of Land Claims. Available online: https:/ / cyfn.ca (accessed on 23 April 2019 ).

61. Government of Yukon. Yukon Science Policy; Government of Yukon: Whitehorse, YT, Canada, 1986.

62. Government of Yukon. Scientists and Explorers Act; Government of Yukon: Whitehorse, YT, Canada, 2002.

63. Government of Yukon. Guidebook on Scientific Research in the Yukon; Government of Yukon: Whitehorse, YT, Canada, 2013.

64. Dedats'eetsaa: Tłıchǫ Research \& Training Institute. Research Agenda. Available online: https://research.tlicho.ca/about/ research-agenda (accessed on 2 June 2020).

65. Government of the Northwest Territories. Knowledge Agenda: Action Plan 2019-2024; Government of the Northwest Territories: Yellowknife, NT, Canada, 2019.

66. Government of the Northwest Territories. Building a Path for Northern Science: Government of the Northwest Territories' Science Agenda; Government of the Northwest Territories: Yellowknife, NT, Canada, 2009.

67. Aurora Research Institute. Doing Research in the Northwest Territories: A Guide for Researchers; Aurora Research Institute: Inuvik, NT, Canada, 2019.

68. Nunavut Tunngavik Inc. Tukisittiarniqsaujumaviit? A Plain Language Guide to the Nunavut Land Claims Agreement; Nunavut Tunngavik Inc: Iqaluit, NU, Canada, 2004.

69. Government of Nunavut. Consolidation of Scientists Act; Government of Nunavut: Iqaluit, NU, Canada, 2013.

70. Rodon, T.; Grey, M. The Long and Winding Road to Self-Government: The Nunavik and Nunatsiavut Experiences. In Northern Exposure: Peoples, Powers and Prospects in Canada's North; IRPP: Quebec, QC, Canada, 2009; pp. 317-343.

71. Makivik Corporation. Nunavik Research Centre. Available online: https://www.makivik.org/nunavik-research-centre/ (accessed on 28 March 2020).

72. Nunatsiavut Government. The Path to Self-Government. Available online: https://www.nunatsiavut.com/government/thepath-to-self-government/ (accessed on 10 March 2020).

73. Nunatsiavut Government. Nunatsiavut Research Centre. Available online: https://nunatsiavutresearchcentre.com/about/ (accessed on 28 March 2020).

74. Nunatsiavut Government. Nunatsiavut Government Research Advisory Committee. Available online: https:// nunatsiavutresearchcentre.com/ngrac/ (accessed on 28 March 2020).

75. Stuhl, A. The Politics of the "New North": Putting History and Geography at Stake in Arctic Futures. Polar J. 2013, 3, 94-119. [CrossRef]

76. Government of Canada. Canada's Northern Strategy: Our North, Our Heritage, Our Future; Government of Canada: Ottawa, ON, Canada, 2009.

77. Government of Canada. Building a Strong Arctic Together: Arctic Policy Framework Discussion Guide; Government of Canada: Ottawa, ON, Canada, 2017.

78. Government of Canada. Polar Knowledge Canada. Available online: https://www.canada.ca/en/polar-knowledge.html (accessed on 22 March 2020).

79. Inuit Tapiriit Kanatami. Arctic and Northern Policy Framework: Inuit Nunangat; Inuit Tapiriit Kanatami: Ottawa, ON, Canada, 2019.

80. Inuit Tapiriit Kanatami. What We Do. Available online: https:/ /www.itk.ca/what-we-do/ (accessed on 6 February 2020).

81. Inuit Tapiriit Kanatami. 2016-2019 Strategy and Action Plan; Inuit Tapiriit Kanatami: Ottawa, ON, Canada, 2016.

82. Inuit Tapiriit Kanatami. National Inuit Strategy on Research: Implementation Plan; Inuit Tapiriit Kanatami: Ottawa, ON, Canada, 2018.

83. Inuit Tapiriit Kanatami; Nunavut Research Institute. Negotiating Research Relationships with Inuit Communities: A Guide for Researchers; Nickels, S., Shirley, J., Laidler, G.J., Eds.; Inuit Tapiriit Kanatami; Nunavut Research Institute: Ottawa, ON, Canada; Iqaluit, NT, Canada, 2007.

84. Nickels, S.; Knotsch, C. Inuit Perspectives on Research Ethics: The Work of Inuit Nipingit. Études/Inuit/Studies 2011, 35, 57. [CrossRef]

85. Petrov, A.N.; Hinzman, L.D.; Kullerud, L.; Degai, T.S.; Holmberg, L.; Pope, A.; Yefimenko, A. Building Resilient Arctic Science amid the COVID-19 Pandemic. Nat. Commun. 2020, 11, 6278. [CrossRef] [PubMed]

86. Vuntut Gwitchin First Nation. Integrated Community Sustainability Plan; Vuntut Gwitchin First Nation: Old Crow, YT, Canada, 2009.

87. World Commission on Environment and Development. Our Common Future; Oxford University Press: Oxford, UK, 1987.

88. Kealiikanakaoleohaililani, K.; Giardina, C.P. Embracing the Sacred: An Indigenous Framework for Tomorrow's Sustainability Science. Sustain. Sci. 2016, 11, 57-67. [CrossRef]

89. Valentin, A.; Spangenberg, J.H. A Guide to Community Sustainability Indicators. Environ. Impact Assess. Rev. 2000, 20, 381-392. [CrossRef]

90. Sheremata, M. Listening to Relational Values in the Era of Rapid Environmental Change in the Inuit Nunangat. Curr. Opin. Environ. Sustain. 2018. [CrossRef]

91. Canadian Polar Commission. The State of Northern Knowledge in Canada; Government of Canada: Ottawa, ON, Canada, 2014.

92. International Expert Panel on Science Priorities for the Canadian Arctic Research Initiative. Vision for the Canadian Arctic Research Initiative: Assessing the Opportunities; Council of Canadian Academies: Ottawa, ON, Canada, 2008. 
93. Rathwell, K.J.; Armitage, D.R.; Berkes, F. Bridging Knowledge Systems to Enhance Governance of the Environmental Commons: A Typology of Settings. Int. J. Commons 2015, 9, 851-880. [CrossRef]

94. Bowen, G.A. Document Analysis as a Qualitative Research Method. Qual. Res. J. 2009, 9, 27-40. [CrossRef]

95. Corbin, J.; Strauss, A. Basics of Qualitative Research: Techniques and Procedures for Developing Grounded Theory, 3rd ed.; Sage Publications: London, UK, 2012; ISBN 9781412906449.

96. Charmaz, K. Constructing Grounded Theory, 2nd ed.; Sage Publications: London, UK, 2014; ISBN 978-0-85702-9133.

97. Karppinen, K.; Moe, H. What we talk about when we talk about document analysis. In Trends in Communication Policy Research: New Theories, Methods and Subjects; Intellect: Bristol, UK, 2012; pp. 177-193.

98. Cardno, C. Policy Document Analysis: A Practical Educational Leadership Tool and a Qualitative Research Method. Educ. Adm. Theory Pract. 2019, 24, 623-640. [CrossRef]

99. Pielke, R.A. The Honest Broker: Making Sense of Science in Policy and Politics; Cambridge University Press: Cambridge, UK, 2007.

100. Berrang-Ford, L.; Pearce, T.D.; Ford, J.D. Systematic Review Approaches for Climate Change Adaptation Research. Reg. Environ. Chang. 2015, 15, 755-769. [CrossRef]

101. Gough, D.; Thomas, J.; Oliver, S. Clarifying Differences between Review Designs. Syst. Rev. 2012, 1, 28. [CrossRef]

102. Gough, D.; Oliver, S.; Thomas, J. An Introduction to Systematic Reviews, 2nd ed.; Sage Publications: London, UK, 2017.

103. Miake-Lye, I.M.; Hempel, S.; Shanman, R.; Shekelle, P.G. What Is an Evidence Map? A Systematic Review of Published Evidence Maps and Their Definitions, Methods, and Products. Syst. Rev. 2016, 5, 28. [CrossRef] [PubMed]

104. Gwich'in Renewable Resources Board. Research. Available online: http:/ /www.grrb.nt.ca/research.htm\#communities (accessed on 16 May 2020).

105. International Arctic Social Sciences Association. Research Principles. Available online: https://iassa.org/about-iassa/researchprinciples (accessed on 23 June 2020).

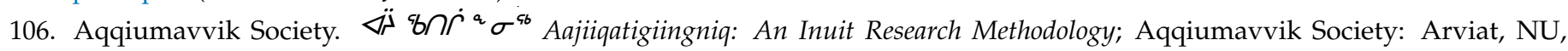
Canada, 2020.

107. Qaujigiartiit Health Research Centre. Our Research Model. Available online: https://www.qhrc.ca/our-approach/our-researchmodel/ (accessed on 16 May 2020).

108. Yukon Research Centre. Protocols and Principles for Conducting Research with Yukon First Nations; Yukon College: Whitehorse, YT, Canada, 2012.

109. Association of Canadian Universities for Northern Studies. Ethical Principles for the Conduct of Research in the North; Association of Canadian Universities for Northern Studies: Ottawa, ON, Canada, 2003.

110. Van Bibber, M.; George, A. Doing Good Health Research in Northern Indigenous Communities: A Guide to Research Review; Arctic Institute of Community-Based Research: Whitehorse, YT, Canada, 2012.

111. Gouvernement du Québec. Québec Research and Innovation Strategy 2017-2022; Gouvernement du Québec: Québec, QC, Canada, 2017.

112. First Nations Centre. Ownership, Control, Access, and Possession (OCAP) or Self-Determination Applied to Research; National Aboriginal Health Organization: Ottawa, ON, Canada, 2005.

113. Inuit Tapiriit Kanatami. Submission to the Naylor Panel for Canada's Fundamental Science Review; Inuit Tapiriit Kanatami: Ottawa, ON, Canada, 2016.

114. Métis Centre. Principles of Ethical Métis Research; National Aboriginal Health Organization: Ottawa, ON, Canada, 2010.

115. Inuvialuit Regional Corporation. Guidelines for Research in the Inuvialuit Settlement Region; Inuvialuit Regional Corporation: Inuvik, NT, Canada, 2013.

116. Dehcho First Nations. Traditional Knowledge Research Protocol; Dehcho First Nations: Fort Simpson, NT, Canada, 2004.

117. Sahtú Renewable Resources Board. Research in the Sahtú Region. Available online: https://www.srrb.nt.ca/index.php?option= com_content\&view=article\&id=145\&Itemid=649 (accessed on 16 May 2020).

118. Council of Yukon First Nations. Traditional Knowledge Research Guidelines: A Guide for Researchers in the Yukon; Council of Yukon First Nations: Whitehorse, YT, Canada, 2000.

119. Simon, M. A New Shared Arctic Leadership Model; Government of Canada: Ottawa, ON, Canada, 2017.

120. Polar Knowledge Canada. Strategic Plan; Government of Canada: Ottawa, ON, Canada, 2020.

121. Government of the Northwest Territories. Traditional Knowledge Policy: Implementation Framework; Government of the Northwest Territories: Yellowknife, NT, Canada, 2004.

122. Healey, G.K.; Walker, J.B.; Heron-Herbert, S. Health Research Ethics in Canada's Northern Territories. 2008. Available online: https://www.qhrc.ca/wp-content/uploads/2019/09/AHRN-Ethics-DEC-2008.pdf (accessed on 16 May 2020).

123. Gwich'in Renewable Resources Board. GRRB Research and Management Priorities 2018-2023; Gwich'in Renewable Resources Board: Inuvik, NT, Canada, 2018.

124. Ferrazzi, P.; Tagalik, S.; Christie, P.; Karetak, J.; Baker, K.; Angalik, L. Describing Aajiiqatigiingniq as an Inuit Consensus Methodology in Health Research; Aqqiumavvik Society: Arviat, NU, Canada, 2020.

125. Ikaarvik. ScIQ: Science and Inuit Qaujimajatuqangit_-Research and Meaningful Engagement of Northern Indigenous Communities; Ocean Wise Conservation Association: Pond Inlet, NU, Canada, 2018.

126. Council of Yukon First Nations. Ownership, Control, Access and Possession of Data (OCAP) Resolution; Council of Yukon First Nations: Whitehorse, YT, Canada, 2006. 
127. Government of the Northwest Territories. Working Together towards Relevant Environmental Monitoring and Research in the NWT; Government of the Northwest Territories: Yellowknife, NT, Canada, 2004.

128. First Nations Information Governance Centre. OCAP: Ownerhship, Control, Access and Possession-The Path To FN Information Governance; First Nations Information Governance Centre: Ottawa, ON, Canada, 2014; ISBN 9780987988287.

129. Government of Canada. Statement on Canada's Arctic Foreign Policy: Exercising Sovereignty and Promoting Canada's Northern Strategy Abroad; Government of Canada: Ottawa, ON, Canada, 2010.

130. Government of Canada. Achievements under Canada's Northern Strategy, 2007-2011; Government of Canada: Ottawa, ON, Canada, 2011.

131. Purple Dog Consulting. Canadian Arctic Research Licensing Initiative (CARLI): Researcher Consultation; Purple Dog Consulting: Ottawa, ON, Canada, 2010.

132. First Nations Information Governance Centre. First Nations Regional Health Survey (RHS)—Best Practice Tools for OCAP Compliant Research; First Nations Information Governance Centre: Ottawa, ON, Canada, 2011.

133. Perrin, A. Narrowing the Gap in Northern Research. North. Public Aff. 2018, 6, 38-40.

134. Brockman, A. Canadian Arctic Research Licensing Initiative: NWT Research Licensing Workshop with Land and Water Regulators; Government of Canada; Aurora Research Institute: Ottawa, ON, Canada; Inuvik, NT, Canada, 2010.

135. Brockman, A. Canadian Arctic Research Licensing Initiative: NWT Research Licensing Workshop Regional/Community Reviewers and Health and Social Science Regulators; Government of Canada; Aurora Research Institute: Ottawa, ON, Canada; Inuvik, NT, Canada, 2010.

136. Irlbacher-fox, S. Developing a Sustainable Knowledge Economy in the Northwest Territories; Hotı̀ ts'eeda; Tłıcho Government: Behchoko, NT, Canada, 2018.

137. Ford, J.D.; Knight, M.; Pearce, T.D. Assessing the "usability" of Climate Change Research for Decision-Making: A Case Study of the Canadian International Polar Year. Glob. Environ. Chang. 2013, 23, 1317-1326. [CrossRef]

138. Brunet, N.D. Assessing Stakeholder Participation in Northern Scientific Research; McGill University: Montreal, QC, Canada, 2014.

139. Institute for Circumpolar Health Research. ICHR Strategic Plan 2015-2020; Institute for Circumpolar Health Research: Yellowknife, NT, Canada, 2015.

140. Council of Yukon First Nations. Yukon First Nations' Research Protocol Template; Council of Yukon First Nations: Whitehorse, YT, Canada, 2018.

141. Gwich'in Renewable Resources Board. Research and Management Interests for the GSA; Gwich'in Renewable Resources Board: Inuvik, NT, Canada, 2018.

142. Inuit Tapiriit Kanatami; Nunavut Research Institute. Negotiating Research Relationships: A Guide for Communities. Pimatisiwin 2003, 1, 17-25.

143. Healey, G.K. Health Research Ethics Workshop and Community Consultation in Rankin Inlet, NU; Qaujigiartiit Health Research Centre: Iqaluit, NU, Canada, 2007.

144. Gwich'in Tribal Council. Conducting Traditional Knowledge Research in the Gwich'in Settlement Area: A Guide for Researchers; Gwich'in Tribal Council: Inuvik, NT, Canada, 2011.

145. Henri, D.A.; Carter, N.A.; Irkok, A.; Nipisar, S.; Emiktaut, L.; Saviakjuk, B.; Ljubicic, G.J.; Smith, P.A.; Johnston, V. Qanuq Ukua Kanguit Sunialiqpitigu? (What Should We Do with All of These Geese?) Collaborative Research to Support Wildlife Co-Management and Inuit Self-Determination. Arct. Sci. 2020, 207, 1-35. [CrossRef]

146. Brunet, N.D.; Hickey, G.M.; Humphries, M.M. The Evolution of Local Participation and the Mode of Knowledge Production in Arctic Research. Ecol. Soc. 2014, 19, 69. [CrossRef]

147. Grimwood, B.S.R.; Doubleday, N.C.; Ljubicic, G.J.; Donaldson, S.G.; Blangy, S. Engaged Acclimatization: Towards Responsible Community-Based Participatory Research in Nunavut. Can. Geogr. Géographe Can. 2012, 56, 211-230. [CrossRef]

148. Government of Yukon; Government of the Northwest Territories; Government of Nunavut. Developing a New Framework for Sovereignty and Security in the North; Government of Yukon; Government of the Northwest Territories; Government of Nunavut: Whitehorse, YT, Canada; Yellowknife, NT, Canada; Iqaluit, NU, Canada, 2005.

149. Blackstock, K.L.; Kelly, G.J.; Horsey, B.L. Developing and Applying a Framework to Evaluate Participatory Research for Sustainability. Ecol. Econ. 2007, 60, 726-742. [CrossRef]

150. Petrov, A.N. Exploring the Arctic's "Other Economies": Knowledge, Creativity and the New Frontier. Polar J. 2016, 6, 51-68. [CrossRef]

151. Polar Knowledge Canada; Pitquhirnikkut Ilihautiniq/Kitikmeot Heritage Society. A Guidebook for Research with Nunavut Communities: Iqaluktuuttiaq (Cambridge Bay) Edition; Polar Knowledge Canada; Pitquhirnikkut Ilihautiniq/Kitikmeot Heritage Society: Cambridge Bay, NU, Canada, 2016.

152. Shirley, J. C-CIARN North-Nunavut Community Research Needs Survey: Summary Report; Nunavut Research Institute: Iqaluit, NU, Canada, 2005.

153. Kawerak Inc.; Raymond-Yakoubian, B.; Raymond-Yakoubian, J. Research Processes and Indigenous Communities in Western Alaska: Workshop Report. 2017. Available online: https:/ / kawerak.org/wp-content/uploads/2018/04/Research-Processes-andIndigenous-Communities-in-Western-Alaska-Workshop-Report.pdf (accessed on 16 May 2020). 
154. Kawerak Inc.; Aleut Community of St. Paul Island; Association of Village Council Presidents; Bering Sea Elders Group. Letter to the National Science Foundation's Navigating the New Arctic Program. 2020. Available online: https://kawerak.org/naturalresources/knowledge-sovereignty/ (accessed on 4 October 2021).

155. Omma, E.M.; Scheepstra, A.; Saxinger, G.; Dale, B. Co-Creating Research Projects-Some Personal Experiences from Saami Council and Arctic Researchers. 2020. Available online: https:/ /www.saamicouncil.net/news-archive/co-creating-researchprojects-some-personal-experiences-from-saami-council-and-arctic-researchers (accessed on 4 October 2021).

156. Stone, R. Indigenous Alaskans demand a voice in research on warming. Science 2020, 369, 1284-1285. [CrossRef] [PubMed]

157. Canadian Institutes of Health Research; Institute of Aboriginal Peoples' Health; Institute of Nutrition Metabolism and Diabetes. Health Research Needs North of 60: Northern Town Hall Meetings, September 2001; Canadian Institutes of Health Research: Ottawa, ON, Canada, 2002.

158. Knapp, C.N.; Trainor, S.F. Alaskan Stakeholder-Defined Research Needs in the Context of Climate Change. Polar Geogr. 2015, 38, 42-69. [CrossRef]

159. Lichen Consulting. Qaujigiartiit Strategic Plan 2018-2028; Qaujigiartiit Health Research Centre: Iqaluit, NU, Canada, 2018.

160. Yukon Initiating Group. Canadian Mountain Network Yukon Initiating Group Discussion Paper; Canadian Mountain Network: Edmonton, AB, Canada, 2017. 